\title{
CLAVES PARA LA COMPRENSIÓN E INTERPRETACIÓN DE UN MOSAICO DE PAISAJES EN LA PROVINCIA DE HUELVA ${ }^{1}$
}

\author{
Jesús Monteagudo López-Menchero \\ Departamento de Historia, Geografía y Antropología. Universidad de Huelva \\ jmonteagudo@uhu.es
}

\section{RESUMEN}

La provincia de Huelva es un territorio entre ríos, Guadiana y Guadalquivir, un discurrir de mesopotamias, de Sierra Morena al Atlántico. Este trabajo aborda el paisaje desde las experiencias vividas, sentidas y emocionadas, puestas de relieve con claves hermenéuticas comprensivas e interpretativas de este ámbito onubense, rico en matices paisajísticos por el entrelazado de todas esas claves. Se presenta el paisaje de Huelva como la síntesis de un todo discontinuo, un discurrir de piezas paisajísticas. Todas están engarzadas y son imprescindibles para completar el puzle, pero ninguna es igual a las otras.

Palabras clave: Paisaje; Huelva; paisajes de montaña; Paisajes de campiña; paisajes litorales; paisajes mineros; paisajes del agua; paisajes periurbanos en tensión; paisajes patrimoniales.

\section{ABSTRACT}

The province of Huelva is a territory between rivers, Guadiana and Guadalquivir, a course of mesopotamias, from Sierra Morena to the Atlantic Ocean. This work approaches

Fecha de recepción: mayo 2016.

Fecha de aceptación: julio 2017.

1 Este artículo se inserta en el desarrollo del Proyecto del MEC: CSO2015-65787-C6-6-P, cuya investigadora principal es la Dra. Rocío Silva Pérez 
the landscape departing from the experiences lived, highlighted with comprehensive and interpretive hermeneutic keys of onubensian field, rich in landscape shades by the interweaving of all those keys. The landscape of Huelva is presented as the synthesis of a discontinuous whole, a course of landscape pieces. All are linked and are essential to complete the whole puzzle, but none is the same as the others.

Keywords: Landscape; Huelva; mountain landscapes; countryside landscapes; coastal landscapes; mining landscapes; water landscapes; outskirts landscapes in tension; patrimonial landscapes.

\section{INTRODUCCIÓN}

Partiendo del carácter normativo y transdisciplinar que imprime al concepto de paisaje el Convenio Europeo del Paisaje (2000), de las ideas sobre paisaje expresadas por J.F. $\mathrm{Ojeda}^{2}$-que ha completado y enriquecido en numerosos trabajos-o D. Cosgrove ${ }^{3}$ y de las que aporta un grupo de investigadores sobre el paisaje que fue pionero y se ha adscrito a esta corriente metodológica ${ }^{4}$, abordando el paisaje desde las experiencias vividas, sentidas y emocionadas, puestas de relieve, transversal y complementariamente con claves hermenéuticas, comprensivas e interpretativas derivadas de la ciencia, la fotografía, la pintura, el relato o la poesía, se plantea un recorrido por el espacio y el territorio de la provincia de Huelva ${ }^{5}$.

Estamos ante un territorio fuertemente patrimonializado, desde arriba -numerosas figuras patrimoniales y de protección establecidas por UNESCO, Ministerio de Cultura o Junta de Andalucía- y desde abajo, desde el sentimiento de patrimonio percibido por sus habitantes y manifestado en multitud de vectores patrimoniales que aún no habiendo recibido ninguna

2 “[...] El paisaje es una especie de ying-yang, una realidad trayectiva o medial, situada entre los elementos constitutivos de un lugar y las percepciones que se emocionan y/o producen emoción con ellos. El paisaje empieza cuando empieza la emoción y, por ello, lo sustancial del paisaje es la 'convergencia de percepciones subjetivas', que se constituyen en patrimonio naturo-cultural, o sea, material-inmaterial, de una comunidad humana. Estamos por tanto ante una 'realidad compleja'[...], resiliente [...] y socialmente aceptable (identitaria, connotada, simbólica, patrimonial)." (Ojeda, J., 2015). Es una idea que conforma el hilo conductor de JF Ojeda en varios de sus trabajos (véase bibliografía Ojeda Rivera, JF.).

3 "Como concepto organizativo y analítico, el paisaje tiene una historia compleja en el marco de la geografía cultural. Su uso ha pasado de ser una referencia a lo tangible, un conjunto mensurable de formas materiales en un área geográfica determinada, una representación de esas formas en medios variados como son los cuadros, los textos, las fotografías o las representaciones teatrales hasta llegar a convertirse en los espacios deseados, recordados y somáticos de la imaginación y los sentidos" (Cosgrove, D. 2002).

4 Sería muy larga la relación y como toda relación corre el peligro de dejar muchos nombres detrás, pero valgan algunos pioneros en este sentido, como F. Zoido, R. Mata, J. Nogué, N. Ortega, E. Martínez de Pisón, J. Tort, R. Silva, J. Rodríguez, F. Molinero, B. Delgado, C. Venegas, A. Berque, J. Maderuelo, F. Pillet...(véase bibliografía).

5 No pretende adaptarse metodológicamente este artículo a los resultados para Huelva del Mapa de los Paisajes de Andalucía, que parte de dos niveles: I. Categorías, áreas y ámbitos paisajísticos y II. Unidades fisionómicas, pero sí se tendrá en cuenta este marco general. Igualmente lo abordado aquí no puede tener la complejidad y el carácter holístico que se obtiene en la elaboración del Catálogo de Paisajes de la Provincia de Sevilla (Zoido y Rodríguez, 2014; Mata, 2016). Finalmente, lo que presentamos tiene un carácter completamente distinto del trabajo de clasificación objetiva de paisajes que hacen Alcántara y Muñoz (2015) y está mucho más próximo a lo que plantea J.F. Ojeda (2013 a y b), para quien los paisajes se analizan a partir de categorías como: "límites, componentes principales, atributos y núcleo de sentido". 
figura de protección o nominación oficial, son sentidos, queridos y defendidos por sus gentes como paisajes y elementos patrimoniales que deben ser conservados para las generaciones futuras (Silva, R, Fernández, V. y Mata, R., 2017).

Situada en el extremo suroccidental de la Península Ibérica, con Sierra Morena como tope norte y bañada en el Sur por el Atlántico, esta mesopotamia del Sur de España, entre el Guadiana y el Guadalquivir, unida o separada, según los tiempos, al Portugal del AlgarveAlentexo a través del Guadiana y sus afluentes, y a las provincias de Sevilla y Cádiz a través del Guadalquivir y los suyos, la provincia de Huelva muestra en sus $10.128,5 \mathrm{Km}^{2}$ un mosaico de los más variados y originales paisajes. Los criterios político-administrativos que llevaron a tomar como referencia determinados elementos naturales e históricos para delimitar la provincia en 1833, y sus ajustes posteriores, no anulan sus interrelaciones y su apertura hacia ámbitos colindantes, pero refuerzan su sentido identitario, patrimonial, territorial y cultural, por muy débiles que sean físicamente esas líneas limítrofes o fronterizas.

Se ha publicado una síntesis paisajística comarcal de Huelva por parte de Parejo y Serveto (2008) y son numerosos los autores que desde la multidisciplinariedad se han aproximado a paisajes puntuales, locales o comarcales de la provincia de Huelva. Personalmente, hemos hecho una breve aproximación a los paisajes de Huelva en una aportación al XXV Congreso Nacional de la AGE. Como en aquel, en este trabajo pretendemos presentar el territorio provincial de Huelva como la síntesis de un todo discontinuo, un discurrir de piezas paisajísticas entrelazadas, como las piezas de un puzle. Todas están engarzadas e incluso superpuestas, solapadas, todas son imprescindibles para completarlo, pero ninguna es igual a las otras. Cada una de ellas despierta una sensación distinta, una emoción diferente, porque cada unidad tiene una personalidad propia y cada parte contribuye a enriquecer el conjunto.

Nuestro objetivo se limita a mostrar una síntesis de este puzle paisajístico para dar a conocer el interés de su diversidad y riqueza, con el fin de desarrollar y analizar en profundidad más adelante cada una de estas piezas.

\section{EL ESPACIO ONUBENSE. CLAVES COMPRENSIVAS}

De forma sintética podemos plantear que el espacio sobre el que administrativamente se asienta la provincia de Huelva, como una capa del paisaje holístico resultante, se apoya en una serie de claves para su mirada y comprensión. Serían las siguientes:

1. Está comprendido de Este a Oeste entre dos grandes cuencas fluviales, las del Guadiana y Guadalquivir. Es por tanto un espacio mesopotámico, como ya se ha dicho. No sólo está encajada la provincia entre ríos, sino que sistemáticamente se replican las mesopotamias en su interior, en sucesivos tramos comprendidos entre ríos casi paralelos entre sí y perpendiculares al océano -Guadiana-Chanza, Carreras, Piedras, Odiel, Tinto, Guadiamar-Guadalquivir-. El papel de frontera del Guadiana y su afluente el Chanza se siente fuertemente en el Oeste, porque esa línea constituye una divisoria internacional que a lo largo de la historia ha supuesto un verdadero umbral, un límite cultural apoyado en un accidente fluvial. Un elemento que ha servido más de impermeabilización que de permeabilidad espacial. No menos importante es el papel delimitante de la línea oriental. La Punta de Malandar (Doñana), impulsada por la deriva de poniente, se estira hacia el Sureste alejando la desembocadura del Guadalquivir. Aquí, en el extremo sureste onubense, predomina el vacío humano y la natura- 
Figura 1

MAPA GEOLÓGICO DE LA PROVINCIA DE HUELVA

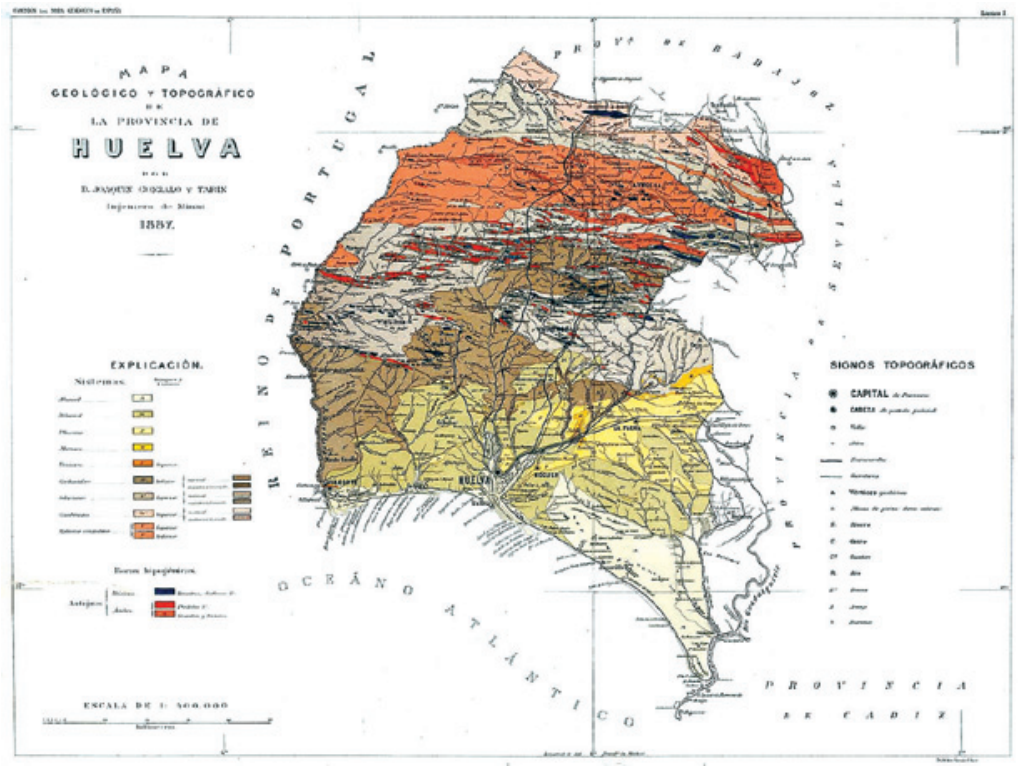

Fuente: Gonzalo y Tarín, 1886.

Figura 2

SIINTESIS GEOLÓGICA DE LA PROVINCIA DE HUELVA

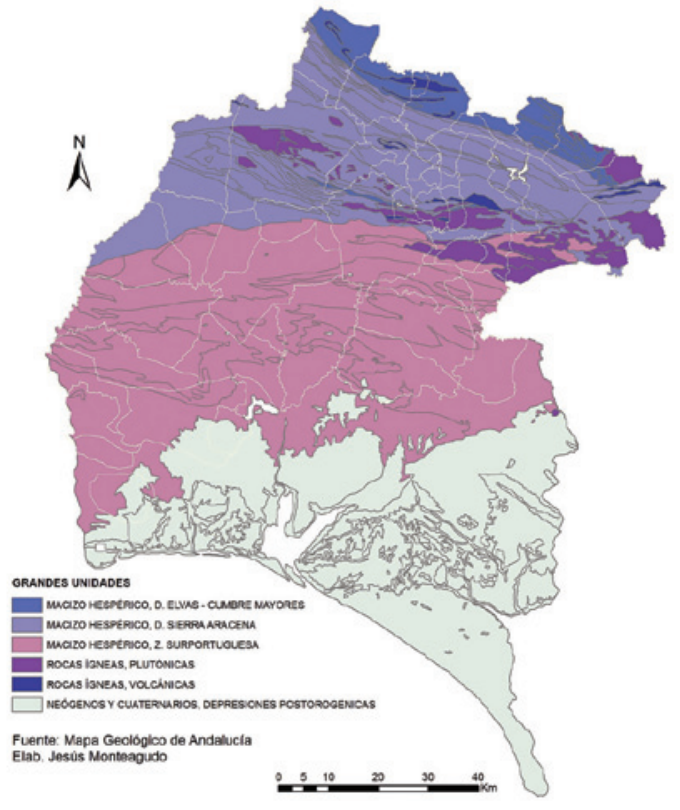


leza -Parques Nacional y Natural de Doñana, marismas, arenas, dunas, pinares, vegetación mediterránea y fauna migratoria-. En este punto desconecta la provincia de Huelva con el otro lado del río, se pierde la conexión directa con los núcleos gaditanos de Sanlúcar de Barrameda y Trebujena, y con el conjunto de núcleos sevillanos como, Lebrija, Las Cabezas o Los Palacios. Por ser el Sur de la provincia de Huelva un espacio en formación permanente y actual, transición entre el océano y el macizo hespérico, la mayor parte de los ríos onubenses terminan en formaciones marismeñas, caños, flechas o restingas.

2. Formando parte del macizo hespérico, Sierra Morena es el límite sur de la Meseta y el norte de Andalucía. La provincia de Huelva reúne en su espacio la parte más ancha de este relieve en sentido Norte-Sur. Más de 7.000 de los $10.128,5 \mathrm{Km}^{2}$ de la superficie de la provincia de Huelva corresponden a esta unidad geomorfológica. Es un espacio muy antiguo, peniplanizado, desgastado, redondeado, rejuvenecido por el plegamiento alpino y conformante de un relieve apalachiense fruto de la erosión diferencial. Los materiales que constituyen Sierra Morena son precámbricos y paleozoicos, magmáticos -ígneos o plutónicos y volcánicos-, metamórficos y sedimentarios: cuarcitas, dioritas, sideritas, granitos, gneis, pizarras, calizas y arcillas, fundamentalmente. En ciertos sectores las rocas que constituyen este relieve están fuertemente mineralizadas por un intenso metamorfismo de contacto, lo que justifica el carácter minero de la provincia (figs. 1 y 2).

El sector más elevado, la Sierra de Huelva propiamente dicha, tiene una superficie de $3.055 \mathrm{~km}^{2}$ equivalente casi a un tercio del total provincial ${ }^{6}$. Por el sector norte de los municipios septentrionales, de Encinasola a Santa Olalla, se prolonga el eje de un anticlinal, quedando al Norte de esta línea la umbría, hacia la penillanura extremeña, y al Sur la solana. El sinclinal que se extiende al Sur de esa línea axial y de Oeste-Este, acumulará en su seno tanto el agua que derraman los arroyos y riveras desde las cumbres, como la que acoge en su interior, poroso y hueco, el macizo calcáreo de Aracena, dando lugar a un espacio de agua y vida en ese seno transversal de la Sierra. Existe un nudo hidrográfico que conforma una divisoria de aguas hacia las cuencas del Guadiana -Chanza y Múrtigas- y Guadalquivir -Riveras de Huelva y del Cala-. En este ámbito, gracias al relieve apalachiense, se puede dirigir la mirada desde las cumbres más altas, formadas por rocas más resistentes -pico Los Bonales, el más alto de la provincia, 1.055 m. en Arroyomolinos de León; mirador del puerto de Alájar, 820 m. en Alájar-Fuenteheridos- hacia el mar y permite ver un espacio peniplanizado, redondeado, desgastado y erosionado, con alternancia de sierras y valles, hondonadas y cumbres en un horizonte abierto que se repite hasta donde alcanza la vista, en un progresivo descenso hasta el Sur (fig. 3 arriba).

Desde el punto de vista climático el espacio onubense pertenece al clima mediterráneo, matizado en el Sur por el océano Atlántico, que lo convierte en un clima mediterráneooceánico de mayor pluviosidad que las tierras situadas hacia el Este. En la clasificación de Köppen es un Csa. El interior de la provincia tiene un clima mediterráneo continentalizado y matizado por la altitud en el Norte, que refresca las temperaturas y aumenta la precipitación, dando lugar a un clima más húmedo y fresco que en el Sur. Los suelos son esqueléticos, excepto en el sinclinal calcáreo, en el que la acción del agua ha erosionado la caliza y constituido suelos rojos aptos para la agricultura en los ruedos de los pueblos, como Galaroza

6 De esta superficie, 1.868,27 $\mathrm{Km}^{2}$ corresponden al Parque Natural Sierra de Aracena y picos de Aroche. 
o Fuenteheridos. Es un espacio climax de la vegetación arbórea mediterránea de encina (Quercus ilex) y alcornoque (Quercus suber), a los que se unen manchas de coscoja (Quercus coccifera), quejigo (Quercus faginea) y acebuche (Olea europaea sylvestris). En los terrenos más elevados y húmedos aparecen el roble rebollo (Quercus pyrenaica) y el castaño (Castanea sativa), sobre todo en el sinclinal central en torno a Aracena, Fuenteheridos, Castaño de Robledo y Galaroza, acompañados del matorral mediterráneo -palmito, mirto, coscoja, espino negro, sabina, enebro, lentisco, retama, espliego, lavándula, jara, jaguarzo, romero, tomillo, y plantas herbáceas y bulbosas como los lirios- y algunos representantes de las landas oceánicas, como el brezo, el tojo o la aulaga.

Figura 3

SIERRA MORENA ONUBENSE DESDE EL MIRADOR DEL PUERTO DE ALÁJAR -820 M- (ARRIBA)

Y EL ANDÉVALO. PANORÁMICA DESDE MINA DE LA ZARZA (ABAJO)
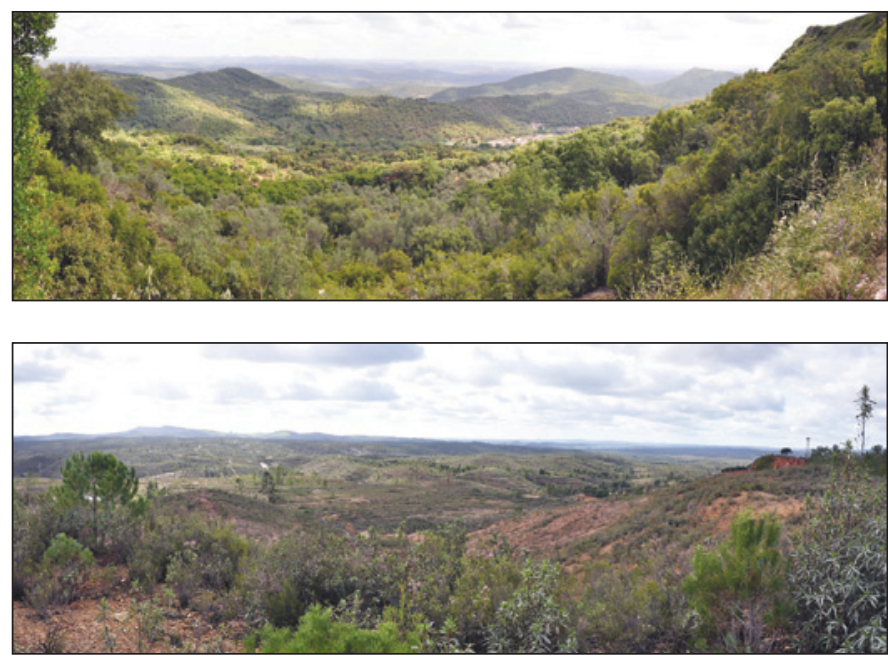

Fotografías: Jesús Monteagudo.

3. La Sierra de Huelva tiene una clara prolongación hacia el Suroeste a través de un espacio duro, rígido, ralo, esquelético, seco, anguloso, cortado, herido, recorriendo el piedemonte de Sierra Morena, que en Huelva se denomina Andévalo. Esta amplia plataforma de casi $4.000 \mathrm{Km}^{2}$ supone tanto una ruptura de pendiente -reflejada en la caída brusca del escarpe Campofrío-Minas de Riotinto- como una continuidad de materiales, en este caso alterados, desertificados, mineralizados. Desde la cuenca del río Tinto, al Este, próxima al límite con la provincia de Sevilla, hasta la raya de Portugal, de Paymogo a Ayamonte, el espacio sigue siendo paleozoico, constituyendo la llamada faja pirítica del suroeste peninsular (Gonzalo y Tarín, 1886). Está surcado por los principales ríos interiores ya citados. La identidad de estos ríos está marcada por la pendiente Norte-Sur, por los materiales piríticos que atraviesan, por el color rojo y ácido de sus aguas herrumbrosas, teñidas por las labores mineras en su lixiviación -topónimos como Tinto, Tintillo, Agrio...-, por la deriva marítima del Oeste y por el carácter marismeño y arenoso de sus desembocaduras. Este territorio tiene un clima 
continentalizado y más seco que en el Norte. La vegetación original es similar a la de la Sierra, pero es un espacio muy degradado y deforestado por el papel histórico que la vegetación ha representado en la explotación minera y por las intensas repoblaciones de eucaliptus de la segunda mitad del siglo XX (fig. 3 abajo).

4. El sector meridional del interior de la provincia, mesopotámico una vez más, entre el río Guadiana y el Guadiamar-Guadalquivir, sobre todo entre el Odiel y el Guadiamar-Guadalquivir, es la Campiña, la Tierra Llana de Huelva (Gonzalo y Tarín, 1886; Terrero, 19521954). Está formado por materiales más recientes, desde las calizas secundarias de Niebla hasta arcillas rojas, margas y arenas plioceno-cuaternarias del Sureste, más jóvenes cuanto más al Sur. La Campiña se encuentra entre los rasgos climáticos del Andévalo y la Costa, elevándose la temperatura y agudizándose la aridez mensual conforme se acerca al valle del Guadalquivir. Es un espacio apto para la vegetación arbórea mediterránea de encinas y alcornoques, a los que se unen los pinos, en especial el pino piñonero (Pinus pinea), acompañados del matorral mediterráneo y de hierbas y plantas psamófilas, por la proximidad de las arenas costeras. Por sus suelos profundos y laborables es un espacio deforestado, muy labrado, que soporta la mayor actividad agrícola de la provincia, sobre todo de la trilogía mediterránea.

Tabla 1

VALORES CLIMÁTICOS PROVINCIALES

\begin{tabular}{|l|c|c|c|c|c|}
\hline $\begin{array}{l}\text { VALORES CLIMÁTICOS } \\
\text { (Csa de Köppen) }\end{array}$ & $\begin{array}{c}\text { TEMP. MÁX. } \\
\text { AGOSTO }\end{array}$ & $\begin{array}{c}\text { TEMP. MÍN. } \\
\text { ENERO }\end{array}$ & $\begin{array}{c}\text { TEMP. } \\
\text { MEDIA } \\
\text { ANUAL }\end{array}$ & $\begin{array}{c}\text { PREC. } \\
\text { ANUAL } \\
\text { mm }\end{array}$ & $\begin{array}{c}\text { MESES } \\
\text { ÁRIDOS }\end{array}$ \\
\hline ARACENA (Sierra) & 31,6 & 2,7 & 14,7 & 677 & jun-sep \\
\hline CALAÑAS (Andévalo) & 31,1 & 5,3 & 16,5 & 551 & may-sep \\
\hline $\begin{array}{l}\text { LA PALMA DEL CONDADO } \\
\text { (Campiña) }\end{array}$ & 31,7 & 6,4 & 17,7 & 524 & may-sep \\
\hline AYAMONTE (Costa occ.) & 29,6 & 7,6 & 17,5 & 482 & may-sep \\
\hline HUELVA (Costa central) & 29,5 & 7,7 & 17,8 & 467 & may-sep \\
\hline $\begin{array}{l}\text { MATALASCAÑAS-EL ROCíO } \\
\text { (Costa orient) }\end{array}$ & 30,2 & 7,2 & 17,8 & 522 & may-sep \\
\hline
\end{tabular}

Fuente: https://es.climate-data.org Elaboración: Jesús Monteagudo

5. La costa atlántica onubense, desde la desembocadura del Guadiana al Guadalquivir, de $122 \mathrm{Km}$ de longitud, es una costa de arenas finas oceánicas, fraccionada y compartimentada por ríos y esteros perpendiculares al océano, paralelos entre sí e influidos por la deriva constante y dominante del Oeste, como ya se ha explicado, rasgo imprescindible para comprender la forma litoral de la provincia, interrumpida con frecuentes flechas y restingas y la prolongación hacia el Sureste de la Punta de Malandar, en el sector central del Golfo de Cádiz. Se ha visto afectada durante el Cuaternario por constantes transgresiones y regresiones marinas (Borja y Díaz, 1995; Rodríguez, J. y Núñez, C., 2015), lo que se refleja en su original morfología de costas arenosas, largas y amplias, con importantes escarpes de playas colgadas y dunas y esteros fósiles por el efecto isostático y eustático (Menanteau y Vanney, 1985). Es 
una costa en la que la dinámica marítimo-terrestre sigue muy activa, especialmente en el centro y sureste del litoral de la provincia. Fue alterada por el maremoto de Lisboa de 1755.

Desde el punto de vista climático y biogeográfico la Costa tiene un clima mediterráneo con menor oscilación térmica que el resto de la provincia, por la influencia del océano, y su temperatura aumenta levemente de Oeste a Este, hacia el valle del Guadalquivir. La elevada humedad relativa del aire facilita la supervivencia de la vegetación. La climax es la vegetación psamófila, como los extensos pinares de pino piñonero, sabinas, enebrales, lentiscos, mirtos o arrayanes y además persisten numerosas especies arbustivas y herbáceas. En Doñana hay alcornoques que sirven de pajareras a las espátulas y garcillas y en los ámbitos más consolidados se extiende una rica variedad de vegetación mediterránea de plantas aromáticas. Existe además una rica flora de vegetación halófila como la siempreviva, almajo, tomillo sapero. Es necesario tener en cuenta que en los humedales que componen la costa de Huelva, espacios híbridos y de movilidad constante e imagen mutante -pleamar-bajamar; agua salada-agua dulce; cambios estacionales de follaje, ramificación y floración; dunas móviles; sequía estival...-, protegidos con diversas figuras, desde las internacionales a las autonómicas pasando por las nacionales, como Doñana o Marismas del Odiel, existe una rica fauna que añade más interés a estos ecosistemas, tal es la biodiversidad de reptiles, mamíferos -algunos en peligro de extinción, como el lince ibérico- y las migraciones y cría de aves (Rubio, 1977). Finaliza el espacio costero provincial de Huelva en el océano Atlántico, el mar abierto que lo conecta con el mundo.

En síntesis, el espacio provincial onubense es un espacio confinado, mesopotámico, entre la Meseta y el Atlántico. Tanto más elevado y más antiguo geológicamente cuando más al Norte. Desciende en altitud y rejuvenece hacia el Sur, sobre todo hacia el Sureste, hasta llegar al Atlántico, siendo la ría de Huelva, las marismas del Odiel, Doñana y las marismas del Guadalquivir los mejores ejemplos de espacios inacabados, en continua formación y transformación. Litológicamente va desde las rocas ígneas y metamórficas en el Norte, muy mineralizadas en el Andévalo, hasta las calizas de Niebla, margas y arcillas de la campiña y arenas de la costa. Su morfología apalachiense, la dirección armoricana del macizo hespérico, las fracturas provocadas por el plegamiento alpino y la irregularidad de su superficie produce numerosos compartimentos con alto grado de aislamiento y singularidad. El clima mediterráneo, Csa, es más continentalizado húmedo y fresco en el Norte, va perdiendo precipitación y aumentando temperatura hacia el Sur y ya en la costa disminuye la oscilación térmica. Las células espaciales compartimentadas por el relieve provocan numerosos microclimas y ecosistemas en toda la provincia. La vegetación predominante es la mediterránea, enriquecida por plantas psamófilas y halófilas en el litoral. Tal variedad de biotopos, desde la tectónica, litología, geomorfología, edafología, climatología, hidrología y botánica genera una riquísima variedad de biocenosis faunística en los diferentes ecosistemas que se conforman.

\section{EL TERRITORIO DE HUELVA. CLAVES INTERPRETATIVAS}

Sobre los espacios descritos, escenarios naturales, se sobreimpone un territorio altamente antropizado y patrimonializado, pero gravemente desconectado del resto del territorio nacional e internacional. Un fondo de saco, un final de trayecto, confinado, fuertemente coloni- 
zado, marginado, olvidado e invisibilizado. Desde la Edad Moderna hasta hoy únicamente ha formado parte de la memoria colectiva como tierra de descubrimiento, explotación, expolio, aprovisionamiento, disfrute y conservación de la naturaleza. En distintas épocas de la historia ha servido de encrucijada de caminos y pueblos, pero en la actualidad se puede considerar desconectado de los principales ejes de transporte y comunicaciones de España y bipolarizado: una profunda geografía del abandono, la despoblación y el envejecimiento en el Norte y Oeste y una viva geografía insostenible de ocupación agrícola, turística, urbanística e industrial en el Sur. Ambos casos, abandono y sobreexplotación, son problemas ambientales graves. En el primero hay una pérdida importante de cultura y patrimonio y en el segundo una presión altísima sobre los factores limitantes: agua, suelo, energía y residuos.

Las claves interpretativas territoriales pueden resumirse en las siguientes:

1. Rico pasado histórico y cultural, del Neolítico a nuestros días. Numeroso e importante patrimonio natural, arqueológico y monumental de las distintas épocas históricas y claras huellas de la ocupación humana por todo el territorio. Protección del patrimonio natural y cultural en ámbitos de singular belleza e interés natural, histórico y antropológico, como la Sierra de Aracena y Picos de Aroche, Doñana y las Marismas del Odiel; monumentos megalíticos del Neolítico -dólmenes de Soto, del Pozuelo...-; yacimientos y actividad tartésica -cabezo de la Joya, Tejada la Vieja, ss. IX-VII a.C.-, turdetana y céltica, como la Baeturia Celtica, asociados a la explotación minera y a la actividad comercial con los pueblos del Mediterráneo. Roma explotó sus minas, ocupó y aumentó el poblamiento, -núcleos como Turobriga, Aruci, Ilipla, Ituci, Onuba Aestuaria..., amplia explotación minera en Riotinto donde existen restos de útiles de minería, esculturas, galerías, norias, escorias, necrópolis... y extensas calzadas romanas que conectaban El Guadiana con Hispalis y Onuba y con Emerita Augusta-Vía de la Plata- ${ }^{7}$.

2. Amplias huellas de la época musulmana reflejadas tanto en topónimos por toda la provincia en núcleos de población y ríos -la provincia y capital toman el nombre árabe, Welba, y no el romano Onuba-, como en restos andalusíes y mudéjares diversos, tales como monumentos, obras públicas, gastronomía, costumbres, fiestas, técnicas agrarias, muestras todas ellas del elevado interés de este sector occidental de Andalucía para la cultura islámica. Huelva pertenece a la Ruta de Al-Mutamid, entre cuyos monumentos figuran el conjunto monumental de Niebla, la mezquita de Almonaster, el castillo de Aracena, La Rábida...

3. La reconquista y repoblación cristianas son claves para comprender la influencia exterior en el rico patrimonio de la provincia, en repoblaciones forestales, expresiones lingüísticas, folclore, fiestas, romerías, arquitectura popular, costumbres y gastronomía. El territorio fue repoblado por gentes del Norte de España, leoneses, asturianos y gallegos. Las razzias con portugueses y las contiendas entre las órdenes militares -templarios en Aracena, orden de Santiago en los núcleos “de León”- llevaron a la construcción de la Banda Gallega, línea de fortalezas y castillos que coronan todo el Norte de la provincia (Carriazo, 2004 y 2008; Pérez Macías y Carriazo, 2005). El poblamiento de la zona, muy disperso, refleja las tensio-

7 Existe una amplia bibliografía, imposible de recoger toda en este artículo, sobre estos temas por parte de un grupo de investigadores, arqueólogos de la Universidad de Huelva: Juan Aurelio Pérez Macías, Juan Campos Carrasco, Juan Luis Carriazo, Francisco Gómez Toscano, José María Rincón, Nuria de la O Vidal Teruel, Aquilino Delgado, Francisco Borja y otros. Remitimos a estos autores en bases de datos bibliográficas, como Dialnet, para consultar ampliamente su extensa obra sobre estas cuestiones. 
nes del territorio. En definitiva, proliferación y abundancia de fortalezas, fronteras, límites e hitos festivos, cruces de mayo, romerías, santuarios, morabitos y belvederes, patrimonio todos ellos de este cruce de culturas.

4. Los repartimientos de tierras en la Baja Edad Media fraccionaron en dos la provincia actual. El Norte quedó mayoritariamente como tierra de realengo, mientras que el Sur fue repartido entre la nobleza: ducado de Medina Sidonia, Condado de Niebla, Marquesado de Gibraleón, Marquesado de Ayamonte, Señorío de Tenorio-Portocarrero en Moguer... De este reparto derivan las actuales estructuras de propiedad y explotación de importantes extensiones de tierra en la provincia (Ladero, 1976; Ojeda, 1987). La Campiña, ocupada en su mayoría por El Condado de Niebla y otros señoríos, generará campos abiertos con cultivos de la trilogía mediterránea: trigo, vid y olivo en régimen de grandes propiedades, aunque en la actualidad la propiedad se ha ido fraccionando y disminuyendo hasta predominar la pequeña y mediana propiedad. El Norte y Oeste provinciales, mayoritariamente montes comunales, montes públicos, al derivar de tierras de realengo, fueron fuertemente deforestados por las compañías mineras en el siglo XIX y repoblados de eucaliptos en la segunda mitad del siglo XX.

5. Al finalizar el siglo XV parten de Huelva las tres naves que al mando de Cristóbal Colón descubren América. El puerto de Palos de la Frontera, La Rábida y el papel jugado por los hermanos Niño, de Moguer, harán de este territorio desde 1492 una referencia mundial. Son conocidos desde antaño como Lugares Colombinos por el protagonismo que tuvieron en la hazaña.

Durante el reinado de Felipe II fueron diseñadas las conocidas como torres almenaras que flanquean la costa de Huelva, desde la desembocadura del río Guadiaro, en Cádiz, hasta Faro, en Portugal. Constituyen un elemento identitario y patrimonial de la costa de Huelva ${ }^{8}$.

6. En el siglo XVIII comienza la explotación intensiva de las pesquerías en La RedondelaIsla Cristina por parte de compañías catalanas (Gozálvez, 1999; Sáñez, 1791-95). Las salazones pasan a ser un referente gastronómico-cultural de esta costa onubense para toda España y este territorio comienza a adquirir una relevancia que proseguirá en los siglos posteriores.

7. En 1833 Huelva fue designada capital provincial. Apenas existían comunicaciones interiores, Huelva era un puerto en el sector central del arco marítimo provincial, erigiéndose en lugar central de un hinterland litoral que abarcaba de Ayamonte a Sanlúcar de Barrameda, pero que se prolongaba más allá hacia Portugal y hacia Cádiz y Sevilla. El mar cobra la relevancia que no tiene el interior, despoblado y mal comunicado (Gozálvez, 1982).

8. A finales de la década de 1860 , en pleno período del modelo colonial, se ponen en explotación las minas de Tharsis y en 1873 las de Riotinto. La I República Española les vende a las compañías mineras extranjeras, a perpetuidad, el subsuelo, el suelo y el vuelo. Desde ese momento se impone en Huelva el modelo colonial: mina-hábitat-ferrocarril-puerto -con muelles tan representativos como los de las Compañías de Tharsis y Rio Tinto sobre el Odiel

8 Tenían como finalidad proteger estos territorios de los ataques de los piratas berberiscos y de los turcos otomanos, cuyas incursiones y saqueos terminaban a menudo con éxito, llegando hasta Sevilla. Fueron construidas durante el reinado de Felipe IV, siglo XVII. La provincia está surcada por al menos 11 torres almenaras, algunas ya desaparecidas y de otras sólo quedan restos porque dada su situación, al mismo borde el mar, han sufrido la erosión marina. Van desde Torre Canela, en el Guadiana, hasta Torre de San Jacinto en la Punta de Malandar, pasando por las de La Higuerita, del Catalán, Punta Umbría, Arenillas, Morla, del Loro o del Oro, del Asperillo, de La Higuera, de Zalabar y Carboneras (Mora Figueroa, 1981). 
(Chapela, 1999) o el puerto de La Laja, sobre el río Guadiana (El Granado)-. El resto del territorio no intervenido por estos elementos era invisible o estaba al servicio de ellas. Las consecuencias de esta explotación minera en el territorio, patrimonio, paisaje y sociedad podemos sintetizarlas en las siguientes:

a) En primer lugar, se genera en la cuenca minera de Riotinto y en la Sierra uno de las mayores impactos ambientales conocidos en toda su historia. Se trata de la calcinación de pirita al aire libre, por tostación o método de calcinación natural. Por la forma aplastada semejante a un pan de la zona se les llamó el sistema de teleras ${ }^{9}$.

b) La segunda consecuencia sobre el territorio es la explotación masiva de pirita que a partir de entonces se hace a cielo abierto. El territorio se llena de cortas. Esa explotación supone la extracción de volúmenes ingentes de mineral (Gonzalo y Tarín, 1886; Pinedo, 1963; Ferrero, 2000). No sólo se extraen cantidades nunca antes conocidas, sino que además se explotan los mejores filones, dejando esquilmada la minería onubense hasta nuestros días.

c) El tercer efecto es la llegada masiva de inmigrantes a trabajar en las minas. En una época de tan escasa mecanización la mano de obra, explotada y empobrecida, es muy numerosa. Venía de toda Huelva, Sevilla, Extremadura y Portugal. La población creció en el último tercio del siglo XIX de forma exponencial.

d) En cuarto lugar, como consecuencia de lo anterior, se produjo la extensión y multiplicación del poblamiento del Andévalo y la Sierra. Los municipios aumentaron explosivamente su población y las aldeas y núcleos secundarios crecieron y se multiplicaron. La falta de transportes y medios de comunicación obliga a que cada mina tuviera en su proximidad un poblado, altamente controlado por la compañía respectiva, en formas arquitectónicas y en libertades y costumbres sociales. Crecimiento y multiplicación de núcleos de población llevaron pronto a la segregación de algunas aldeas de sus municipios matrices. Fue lo ocurrido con las aldeas de Minas de Riotinto, Nerva y El Campillo, que se segregaron de Zalamea la Real y formaron nuevos municipios.

e) La actividad minera continuó durante el siglo XX, con huelgas importantes en 1900, 1913 y 1920, ya en plena I Guerra Mundial. Siguió la explotación minera en la II República, Guerra Civil y Franquismo. La represión obrera fue durísima tras la Guerra Civil y el territorio se pobló de terror, miedo, odio y silencio en la población. En 1954 se "nacionalizan" todas las minas. Se explotaron hasta finales de los años ochenta del siglo XX con mayoría de capital español y con distintas figuras empresariales, hasta que finalmente se cerraron la mayoría al iniciarse el siglo XXI. La minería se ha vuelto a recuperar en la década de 2010 como consecuencia de la globalización, de la mejora

9 Las teleras son sobre todo de la cuenca de Riotinto, produjeron una alta concentración de humos sulfurosos, tóxicos para la población y letales para los cultivos de la zona. Causaron una altísima deforestación en la zona ya que las compañías eran también dueñas del vuelo de los montes comunales, que fueron masivamente utilizados como leña. Provocaron la rebelión de los obreros y la unión de estos con los caciques agrícolas. La unión de los descontentos provocó una manifestación conjunta de obreros y agricultores que terminó en matanza al disparar el ejército sobre los manifestantes. Se considera la primera manifestación ecológica de la historia y su final fue sangriento. Era el 4 de febrero de 1888 y quedó en la memoria colectiva como año de los tiros (Ferrero, 1994; Chastagnaret, 2017). 
de las técnicas de extracción y de la subida del precio de los metales, sobre todo cobre, plata y oro. El Andévalo vuelve a mostrar la fisonomía de la actividad minera, sin embargo, en la mayoría de los casos las cortas siguen cerradas, con graves problemas ambientales.

9. Tras la autarquía franquista, el modelo neocolonial llega a Huelva a partir de la Planificación del Desarrollo y los Polos. Huelva es designada en 1964 Polo de Promoción Industrial por la existencia de las minas de piritas de Riotinto y Tharsis, por el descubrimiento de nuevas minas en el mundo, por la bajada del precio de la pirita exportada en bruto, por la necesidad de concentrarla y obtener in situ las plusvalías de tal transformación y por la existencia desde 1954 de la poderosa Compañía de Minas de Rio Tinto, de la que eran accionistas los principales ministros tecnócratas de Franco en esa época. Con dinero público, según explicaba Richardson (1976) -en Huelva se invirtió el 75\% de toda la inversión en los primeros siete polos-, se multiplicó el valor de las acciones de la compañía. Esa inversión creó la infraestructura de ese nuevo neocolonialismo, ajeno, por otra parte, a cualquier medida medioambiental: minas, embalses, polígonos industriales, autopista Huelva-Sevilla, ferrocarril industrial, puerto industrial. El resto del territorio quedó invisibilizado y abandonado. Frente a la idea de F. Perroux de que los Polos desarrollaban en círculos concéntricos los ámbitos existentes a su alrededor, en Huelva y otros muchos territorios se comprobó que en realidad funcionan como un cáncer, devorando y eliminando todo lo que hay más allá del área concreta que ocupan, como ocurrió en el centro y norte la provincia de Huelva, que se despoblaron (Fourneau, 1978; Monteagudo, $1987^{\text {a }}$ y 1999).

10. Desde la década de 1960 hasta la de 1980 la provincia de Huelva languideció y se despobló, fundamentalmente en el Andévalo y la Sierra. Su resurgir aparece cuando la agricultura intensiva de fresas en el litoral alcanzó dimensiones dignas de consideración, y ya en los umbrales del siglo XXI por la activación turística de sol y playa, creando incluso una gran tensión en el litoral y espacios protegidos -especialmente por los cuatro factores limitantes: agua, suelo, energía y residuos-. Se produjo una reactivación económica, social y territorial en el litoral y área urbana y periurbana desde finales del siglo XX, como consecuencia de la entrada de España en la CEE, de la bonanza económica de principios del siglo XXI, de la intensificación y diversificación de la agricultura, de la inmigración de población extranjera, del boom inmobiliario y del fomento del turismo de sol y playa. Pero la crisis de 2008 dio al traste con esa euforia y a partir de entonces hasta la actualidad, que comienza a cambiar la tendencia, la provincia perdió población y vio aumentar el cierre de empresas y el desempleo, llegando a ser la de menor número de habitantes de Andalucía -517.594 hab. 01/01/2017- y la de mayor tasa de empleo juvenil de España en 2017. Ni el turismo rural, ni la reactivación de la minería en algunas zonas han salvado la situación crítica, el desempleo, la emigración de jóvenes muy cualificados, el envejecimiento y el vacío del centro-norte de la provincia.

11. Respecto a la conexión y articulación de este territorio, la única vía rápida de la provincia es la autopista A-49/E-01 Sevilla-Ayamonte por San Juan del Puerto, dejando Huelvacapital al margen y dotándola de una red complementaria metropolitana, la H-31, hasta enlazar con la A-49.

La conexión con Extremadura se hace a través de la N-435, Huelva-Zafra-Badajoz, una carretera Sur-Norte de trazado antiguo, de curvas cerradas y continuas, y que transita hasta el 
nudo con la N-433 ${ }^{10}$. El Norte de la provincia, de Este a Oeste está atravesado por la N-433 Sevilla-Lisboa, desde el municipio de Zufre hasta la frontera con Portugal, en Rosal de la Frontera ${ }^{11}$. A la A-66, autovía Ruta de la Plata, Sevilla-Gijón, sólo se puede acceder desde Huelva-capital bien a través de la ya citada N-435, bien desde la A-49 a Sevilla, lo que en cualquier caso produce tanto altos índices de rodeo y aislamiento, como un tiempo y coste excesivos en el desplazamiento.

La conexión con la costa se hace desde Huelva hacia el Este por la N-422 y por la A-494 hasta Matalascañas -Almonte-. Es el final del trayecto provincial por el Sureste. No hay conexión directa Huelva-Cádiz-autopista del Mediterráneo, que tendría que llegar a Sanlúcar de Barrameda a través de Doñana ${ }^{12}$.

Hacia el Oeste, la conexión con Ayamonte se realiza a través de la A-49 ${ }^{13}$. Por el litoral, desde Punta Umbría, la conexión sólo llega a Isla Cristina y está formada por tramos inconexos: A-5050, A-5052, A-5054, A-5055. No hay conexión entre ellos, sólo entre los más importantes núcleos turísticos, porque no hay un puente para salvar el río Piedras, que desemboca en esta zona. Prima la conservación de la naturaleza, pero no se buscan alternativas viables y sostenibles, dejando predominar la desconexión.

Finalmente, como se dijo al comienzo, la frontera hispano-portuguesa es una frontera fluvial, de apenas unas decenas de metros de anchura, excepto el último tramo del Norte provincial que es terrestre, por Rosal de la Frontera. Hasta agosto de 1991 sólo existía este paso fronterizo terrestre. En todo el recorrido fluvial no había ni un solo puente y sí un puesto fronterizo fluvial, cuyo paso se hacía con barcazas, entre Ayamonte-Vila Real de Santo Antonio $^{14}$. Es más que evidente la falta de interés que ha existido por conectar ambos países en este ámbito onubense-algarví-baixoalentexano y con ello esa impresión de finisterre y fondo de saco que ha dado Huelva ${ }^{15}$.

10 Por ella y en el estado descrito circula un tráfico moderado hacia el Norte, especialmente camiones que se dirigen hacia Nerva, al Complejo Medioambiental de Andalucía, un gigantesco vertedero de residuos tóxicos y peligrosos que recoge todas las sustancias que comprenden estas categorías residuales y que proceden no sólo del Polo Industrial de Huelva y de toda Andalucía, sino también de Portugal y otros territorios españoles no andaluces.

11 En su día se intentó desdoblar esta carretera para facilitar el tránsito de Sevilla a Portugal, pero los municipios se opusieron bajo el lema "la Sierra no tiene prisa" por considerarla una carretera paisajista.

12 Hay un consenso general para que se respete el espacio protegido de Doñana, apenas $30 \mathrm{Km}$, pero este hecho no debería haber impedido que se conectase Huelva-Cádiz-autopista del Mediterráneo por el Norte de Doñana. La salida hacia Cádiz ha de hacerse desde Huelva atravesando Sevilla, de nuevo con altos índices de rodeo y aislamiento, aumento de tiempo y costes de desplazamiento.

13 No se han ejecutado adecuadamente ni las conexiones con las cabeceras municipales, ni con los núcleos turísticos del litoral, que utilizan numerosas vías inconexas entre sí.

14 Hasta el 22/08/1991 no se cruza por primera vez el puente internacional sobre el Guadiana, Ayamonte-Castro Marín, con 440 m. de anchura. Hay que esperar hasta el 26/02/2009 para la apertura del segundo puente sobre el Guadiana, el de El Granado-Pomarao-Mértola, de apenas 145 m. de longitud. Finalmente, el 21/04/2012 se abre el puente sobre el Chanza por Paymogo-San Marcos-Serpa, en donde el río tiene menos de $100 \mathrm{~m}$. de anchura. Ha transcurrido toda la historia hasta finales del siglo XX e inicio del siglo XXI sin que ambas orillas fluviales de Guadiana-Chanza se comunicasen por un puente, incluso en tramos en los que el río tiene menos de $100 \mathrm{~m}$ de anchura. Siguen sin conectar por un puente Sanlúcar de Guadiana-Alcoutín, en el centro de la provincia, con una anchura del río de $225 \mathrm{~m}$.

15 Téngase en cuenta, finalmente, para el calificativo de marginación y abandono territorial, sólo un dato: la red autonómica andaluza de carreteras tiene $10.407 \mathrm{Km}$. de longitud; Huelva es la red de menor longitud con $788 \mathrm{Km}$, sólo se le aproxima Almería, con 818, y provincias como Sevilla o Córdoba tienen 1.875 y $1.624 \mathrm{Km}$ respectivamente. Todo ello teniendo en cuenta además que Huelva tiene un hábitat muy disperso en la Sierra, además de necesitar conectarse con dos provincias andaluzas, otra comunidad autónoma y otro país. 
Pese a la larga tradición ferroviaria de Huelva y a que está a $640 \mathrm{Km}$ de Madrid, aún no existe AVE y la vía Huelva-Sevilla procede de los antiguos ferrocarriles del siglo XIX apenas actualizada. Hay que realizar el trayecto Huelva-Sevilla -de $117 \mathrm{Km}$ de longitud invirtiendo $1 \mathrm{~h} 30^{\prime}$, cuando por carretera son $84 \mathrm{Km}$, en $45^{\prime}$ - por una vía antigua y lenta y enlazar en Sevilla con el AVE.

El puerto de Huelva es la principal referencia de comunicaciones nacionales e internacionales de este territorio. Dado el carácter de mercancías cautivas del Polo, es uno de los principales puertos graneleros de sólidos y líquidos de la Red de Puertos del Estado. Recientemente ha iniciado el transporte de pasajeros con Canarias, pero hasta ahora nunca había existido, como tampoco la conexión con los cruceros del Mediterráneo ni del Atlántico. Por lo explicado anteriormente, su hinterland terrestre es muy reducido y apenas sobrepasa la provincia. Las comunicaciones terrestres no fomentan el intercambio intermodal.

En síntesis, un territorio confinado, fronterizo, marginal, finisterre de España por el Suroeste, fondo de saco, mal comunicado, casi inconexo, con umbrales en el Guadiana-Portugal, la penillanura extremeña, el Guadalquivir y el océano Atlántico. Territorio peninsularizado con el istmo en Sevilla, ciudad por donde casi todo pasa desde Huelva y desde donde casi todo llega a Huelva, cuyo tamaño y protagonismo emiten una larga sombra, una umbría hacia el Oeste que produce una alta opacidad sobre Huelva.

\section{LOS PAISAJES DE HUELVA. SÍNTESIS}

Partiendo de las claves comprensivas e interpretativas anteriores, en los espacios naturales onubenses y en su antropización como territorios a lo largo de la historia, se individualizan, amalgamando las distintas capas, una serie de paisajes con elementos tangibles e intangibles, percibidos y sentidos, por las sensibilidades creativas y científicas más diversas. El resultado son paisajes tamizados por sensibilidades y simbologías múltiples que en conjunto constituyen ese puzle del que hablábamos al comienzo. Cada paisaje es una unidad en sí mismo, tiene su propio carácter, su propias señas de identidad, su propio patrimonio, pero todos están engarzados para otorgar al conjunto de este territorio una personalidad distintiva, identitaria y patrimonial (Silva y Jover, 2016; Silva, Fernández y Mata, 2017). Algunos de ellos, tal es su potencia simbólica, representativa e identitaria han pasado a ser definitivamente "archivos paisajísticos de la memoria colectiva". Todos ellos están concebidos bajo la escala intraprovincial, pero no siempre se circunscriben a la comarca, algunos son muy puntuales, otros locales, varios trascienden más allá del ámbito comarcal e incluso si el análisis se hiciese desde otra escala, algunos podrían ir más allá de la escala provincial.

En síntesis, algunos de los paisajes que podríamos encontrar en la provincia de Huelva son los siguientes:

\section{IV.1. Paisajes de dehesa}

El bosque ahuecado de encinas y alcornoques. Paisaje humanizado y domesticado, el trasunto de una cultura, una forma sabia de entender la relación naturaleza-sociedad en el mundo mediterráneo (Ojeda, 2002a), un mundo mítico, simbólico y estético pleno de costumbres y ritos -poda, descorche, matanza, esquila...-, un verdadero patrimonio cultural en la Sierra de 
Huelva (Silva, 2009). Representa la forma más armónica e identitaria conocida entre la conservación de la naturaleza y el aprovechamiento múltiple del bosque: ganadería diversa -porcino ibérico, bovino retinto, ovino, caprino, aves de corral, agricultura de subsistencia, hábitat disperso adaptado al medio, artesanía, gastronomía...-. Todo ello ha generado imágenes gráficas, fotográficas y literarias que identifican y singularizan estos paisajes (fig. 4). La frondosidad del arbolado, la irregularidad del terreno y el vallado de piedra seca producen en la dehesa un sentido de intimidad, de recogimiento interior, de aislamiento, de sucesivas células estéticas y funcionales que juntas forman un organismo completo, pero que cada una de ellas es un mundo en sí misma. Dehesas oscuras y viejas, emblemas de la vegetación mediterránea y el cerdo ibérico, casi inmutables al paso del tiempo. Pese a su carácter de perennifolias, sus atributos estacionales se marcan en la dehesa por la escarcha y la niebla, el cambio de verdor de sus hojas, el estallido del color de las flores que forman la alfombra de su suelo, la fuerte sequía que agosta y dora las hierbas, y la berrea, el celo, el apareamiento y la cría de su fauna y su ganadería. La dehesa es el paisaje más extendido en Huelva, ocupa una extensión de más de 200.000 Ha. Se extiende por todo el Norte y centro de la provincia, dentro y fuera del Parque Natural Sierra de Aracena y Picos de Aroche. Las más bellas y exuberantes dehesas recorren el Norte provincial de Este a Oeste, desde Santa Olalla a Encinasola. Los alcornocales se apropian de los terrenos silíceos del paleozoico serrano, sobre todo en torno a la Sierra de Cala, Cañaveral, Arroyomolinos y las Cumbres. Sus troncos aparecen con el rojo óxido de su savia tras el descorche, aportando mayor contraste de color al paisaje. Las encinas ocupan especialmente el macizo calcáreo central, en torno a Aracena. La actividad minera dañó seriamente las dehesas comunales que por contener mineral en su seno fueron vendidas a las Compañías. En la Sierra afecta sobre todo a dos municipios: Almonaster la Real y Cortegana, pero en el Andévalo prácticamente a todos, con mayor intensidad en aquellos en los que se localizan las más importantes cortas mineras. La emigración de la población a Huelva capital, área periurbana y costa, el envejecimiento de la población, la peste porcina, y los contratos de la Empresa Nacional de Celulosas (ENCE) con los propietarios de dehesas, en un momento en que éstas no estaban protegidas, arrasaron miles de hectáreas en la segunda mitad del siglo XX, especialmente en el OesteSuroeste provincial, siendo sustituida la dehesa por el eucaliptus, una repoblación alóctona y que imprime al paisaje del Andévalo mayor grado de desertificación (Márquez, 1975). En la provincia de Huelva la dehesa representa el tránsito natural, estético y cultural entre el mundo hespérico del Oeste peninsular y el Valle del Guadalquivir y está asociada a un rico hábitat de pueblos fundidos con ella y adaptados a la topografía, a la función histórico-social y a los usos del suelo en su localización, morfología y estructura. Nos permite comprender que, según las épocas, se localizase la población bien en fondos de valle, como Alájar (fig.5) o Linares de la Sierra, con fines agrarios para aprovechar la riqueza del valle y con sentido mimético para pasar desapercibida, en una auténtica simbiosis con el territorio, bien en la parte más alta de las cumbres o en colinas elevadas, como Cumbres Mayores, Aroche, Aracena (fig.7) o Zufre, con un sentido de otero, belvedere, elemento militar, estratégico y defensivo, parte de la Banda Gallega. El ámbito de la dehesa, en la Sierra y el Andévalo, es el que tiene mayor dispersión de la población en aldeas y caseríos $^{16}$.

16 Almonaster la Real (1.891 hab. en 2016) llegó en algunos Nomerclátores de finales del siglo XIX y principios del XX a superar los 30 núcleos dispersos habitados y en el último de 2016 continúa teniendo 17 núcleos dispersos. 
La creación del Polo Industrial de Huelva, junto al abandono rural de la época, la mejora de las comunicaciones y medios de transporte, unido a políticas recientes de carácter ambientalista erróneamente planificadas (Ojeda y Silva, 2002), han provocado un abandono progresivo de la población y un profundo envejecimiento que repercute especialmente en los núcleos de menor población y en las aldeas dispersas, que se despueblan. Ni las distintas figuras de protección del territorio en el ámbito de la dehesa (Ojeda y Silva, 1997), ni las tendencias clorofílicas y el turismo rural (Jurado y Pazos, 2016), ni el neorruralismo, ni la naturbanización (Prados y del Valle, 2010), ni la mayor valoración de los productos del cerdo ibérico, ni los programas Leader y Proder, han conseguido mantener y rejuvenecer la población de la dehesa en Huelva, con el grave riesgo de pérdida ambiental, patrimonial -de un rico patrimonio popular tangible e intangible, antropológico, musical, gastronómico, arquitectónico, festivo y religioso- y de saberes ancestrales que llevan consigo el abandono y vacío humano en un territorio. Aunque además de la dehesa hay otros paisajes en La Sierra y el Andévalo, los municipios de ambas comarcas que albergan dehesas con una superficie significativa representan 51 de los 79 municipios de Huelva -casi el $70 \%$ de la superficie provincial-, acumulándose sobre todo en los 31 municipios de la Sierra. Sin embargo, la Sierra tenía una población en 1930 -censo en que alcanzó su máximo- de 77.334 h. -22\% pob. provincial-y en 2016 fue de 39.287 -7,5\% pob. prov.-. La dehesa se despuebla y envejece.

Figura 4

DEHESA DE ENCINAS. CAÑAVERAL DE LEÓN

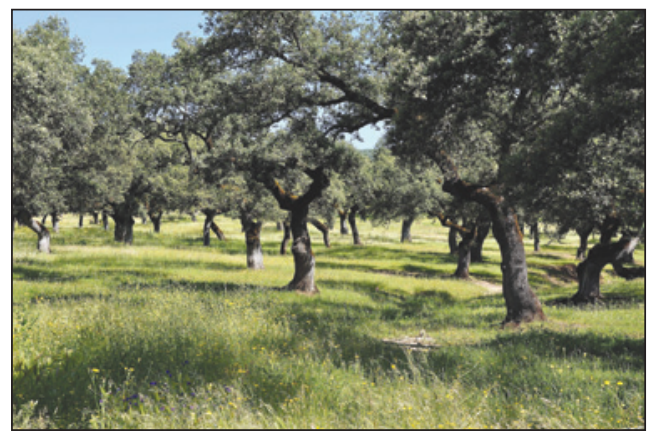

Fotografías: Jesús Monteagudo

\section{IV.2. Paisajes de castaños}

En la Sierra, en altitudes que superan los 600 m, en las zonas más húmedas y calizas de este territorio, el castañar (Castanea sativa) es el símbolo de un ocupación exterior, la repoblación cristiano-medieval con pobladores gallegos. El castaño es una caducifolia de hojas carnosas trasladada del Noroeste al Suroeste de España. En aquel mundo bajomedieval significó aferrarse a lo próximo trasladando incluso el escenario. La mirada del emigrante se familiarizaba con la estética del castaño y con el aprovechamiento de sus frutos en su lugar de inmigración. Forma parte del traslado de una cultura, de un elemento patrimonial con el que seguir identificándose y aferrándose a la imagen del terruño que se ha abandonado, un 
mitigador de morriña, un despertador más del latido de las estaciones. El castañar se incrusta en el territorio de la Sierra, pero representa lo exógeno, lo exótico, lo distinto, la ruptura del verde pardo, la policromía. El verde brillante de las hojas del castaño desde la primavera y el verde claro de los erizos en verano contrasta con el verde pardo de las quercíneas. En invierno el castaño se desnuda ofreciendo una imagen fantasmagórica de brazos agigantados y desnudos y en otoño tiñe de oro, ocre y rojo el paisaje en una inmensa mancha en el corazón de la Sierra (fig. 6). No es muy extenso el castañar en la Sierra, unas 5.000 has., repartidas en fincas de pequeña y mediana propiedad y se localiza en una docena de municipios serranos, pero sirve para trasladar al espectador, al viajero y al turista al mundo oceánico del Norte de España. El ambiente es similar al de la dehesa, con la que comparte el territorio de la Sierra. Sin embargo, junto al castañar aparece como en ningún otro lugar la morfología rural del Norte de España: solaneras abiertas para secar cosechas y hortalizas, muy distintas de las habituales en el mundo mediterráneo andaluz; galerías mirando al sol perfectamente visibles en núcleos como Linares de la Sierra, Alájar, Fuenteheridos, Galaroza, Los Marines, Castaño del Robledo, Valdelarco... Un hábitat rural fundido con el castañar como símbolos patrimoniales de acogida de pobladores de otras tierras. Económica y socialmente la castaña se exporta en crudo sin ninguna transformación, por lo que no genera tejido empresarial ni plusvalías y apenas crea unos pocos puestos de trabajo estacionales. Sólo pequeños artesanos se han atrevido a convertirla en productos autóctonos -mermeladas y marron glacé-. La castaña y el castañar tampoco retienen a la población serrana.

Figura 6

CASTAÑAR ENTRE FUENTEHERIDOS-CASTAÑO

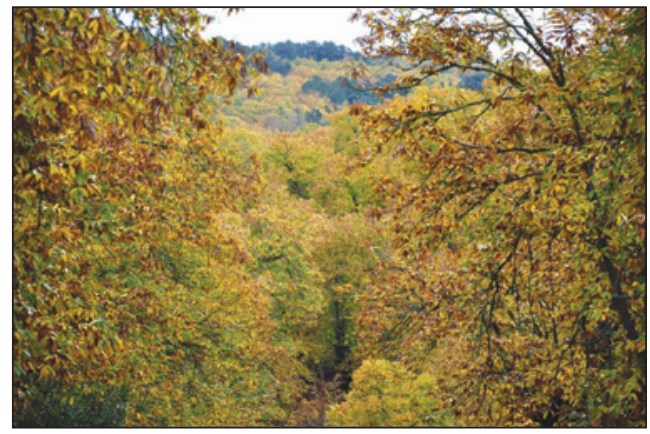

Fotografías: Jesús Monteagudo.
Figura 7

ARACENA. CASERÍO ENCARAMADO AL CASTILLO

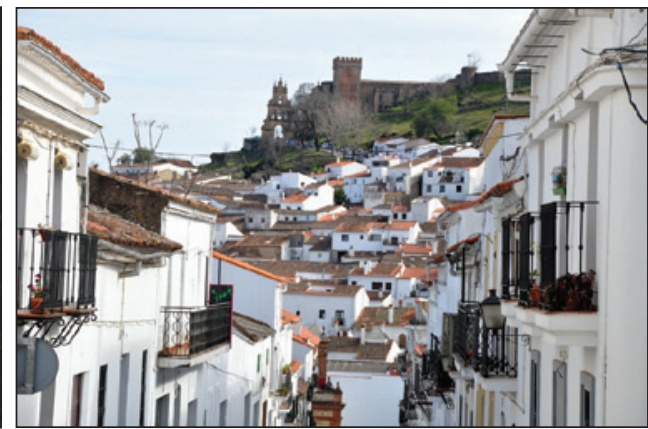

\section{IV.3. Paisajes de agricultura serrano-andevaleña}

Además de estos paisajes forestales, existe una puntual agricultura de frutales y hortalizas en todo el terreno paleozoico, ferazmente regada por las aguas del macizo de Aracena y los ríos, riveras y arroyos del Norte provincial, y que constituyen un pequeño mosaico de colores, olores y sabores en el corazón de la Sierra, a menudo en los ruedos de los pueblos. Es el agua la que ha permitido un variado policultivo de huerta en los municipios serranos, 
con frutas tan conocidas como "los peros" de Galaroza o los melocotones de La Nava. Esta agricultura, que ha formado parte de la tradición y la sostenibilidad de esta zona, ha ido desapareciendo y en la actualidad es residual y simbólica. Asimismo, existen manchas de olivo de montaña en los municipios del norte provincial, que se aproximan a las 9.000 has.

La agricultura andevaleña apenas se localizaba en el ruedo de los pueblos y en algunos municipios tradicionales de agricultura, como Zalamea la Real. Ahora se extiende cada vez más gracias a las modernas tecnologías de riego y al abandono minero, como ocurre con los naranjos de la Rio Tinto Fruit SA, una extensión de más de 1.600 ha. de cítricos y frutales sobre terrenos de las minas de la Rio Tinto, que ponen una nota de color verde intenso en el rojo y gris de las minas y ofrecen una imagen de ordenación geométrica de bancales en un paisaje irregular de escombreras y cortas. O como sucede en el Andévalo occidental donde la agricultura de naranjos, olivos e invernaderos se ha ido extendiendo y salpicando el paisaje con estos colores verdes de los naranjos y olivares, y manchas de plásticos, aislados entre sí y que introducen siempre esa sensación de domesticación de una tierra salvaje, adusta e indomable, tierra de minas y eucaliptus.

\section{IV.4. Paisajes del agua}

El agua es la esencia de la Sierra, no sólo porque su precipitación alcanza $700 \mathrm{~mm}$. anuales, sino porque en algunos puntos esa precipitación supera los $1.000 \mathrm{~mm}$ y se acumula en el macizo cárstico de Aracena, siendo filtrada y emanada a lo largo de todo el año por los manantiales o surgencias. El agua determina algunos topónimos: Cañaveral, Arroyomolinos, Fuenteheridos, que reflejan su papel incluso en labores de molienda. En los municipios citados el agua forma parte de sus vidas cotidianas, del paisaje de sus pueblos, ruedos y huertos e incluso de su ocio, como ocurre en el "pilar", la acequia o lieva y "laguna" de Cañaveral de León, un manantial, una acequia y una alberca que protagonizan la plaza del pueblo y que incluso sirve de baño popular municipal (fig. 8). Otro tanto ocurre en todo el ámbito del entorno de Aracena y en la misma Aracena, cuyas grutas mantienen el discurrir del agua de forma constante.

Pueblos como Galaroza, Fuenteheridos y Alájar tienen fuentes "de los doce caños", manantiales permanentes. Igual ocurre con abrevaderos y lavaderos que, situados en los fondos de los núcleos de población, han recogido y utilizado de forma práctica y con una larga tradición el agua de sus manantiales, como ocurre en Linares de la Sierra, Aracena, Corteconcepción o Zufre, constituyendo verdaderos vectores patrimoniales de la cultura del agua. La misma agua que forma bosques galería con chopos, álamos, fresnos y todo tipo de árboles de ribera, mostrando la viveza y el colorido estacional. El agua que imprime el carácter de los pueblos serranos está presente en multitud de vectores patrimoniales que ya se han nombrado, arroyos, riveras, bosques galería, manantiales, molinos, fuentes, lavaderos, abrevaderos, norias, huertos, incluso en embalses, como los de Aracena, Campofrío o Zufre. Señas de identidad, todos ellos, de pueblos de agua.

El paisaje del agua en Huelva es también el paisaje de sus ríos. Ya hemos dicho que Huelva es una continua mesopotamia, en la provincia y en cada una de sus subunidades territoriales. Los ríos la ciñen, la riegan, le dan color, identidad y personalidad. No se entenderían los paisajes de Huelva sin el rojo herrumbroso del río Tinto y de todos los afluentes y riveras por cuyo discurrir entre minas y escombreras colorean los cauces. Incluso el Andévalo es la reserva de 
agua para Huelva. El embalse homónimo tiene una capacidad de $600 \mathrm{Hm}^{3}$ y por doquier, junto a cada mina, hay una presa, un "dique", para lavar mineral. La imagen aérea del Andévalo es la de un paisaje de rojo mineral, de tintas y negras aguas piritíferas y de profundos embalses, como manchas negras salpicando el territorio. Huelva tiene una capacidad de embalse de 1.500 $\mathrm{Hm}^{3}$ repartidos por toda la provincia, especialmente en el Andévalo y la Sierra.

Figura 8

CAÑAVERAL DE LEÓN. ELAGUA LLEGA POR UNA LIEVA A LA "LAGUNA" Y SALE POR OTRA A LOS CAMPOS
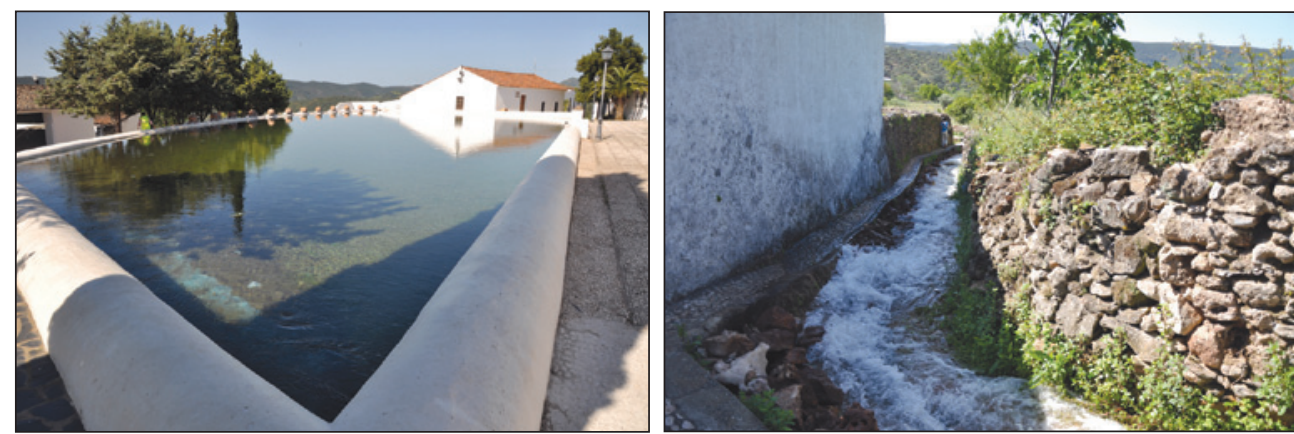

Fotografías: Jesús Monteagudo.

Finalmente en el Sur de Huelva el agua no sólo está en el océano Atlántico, también en el borde litoral-continental, con los espacios marismeños como protagonistas (véase apart. IV.8).

\section{IV.5. Paisajes mineros}

Junto con el agua y la dehesa, la mina es la que más señas de identidad patrimonial aporta a los paisajes de Huelva, pese a su carácter puntual. La minería representa las venas abiertas de la tierra, el rojo sangre del organismo mineral, la fusión entre una tierra de promisión, como la California del oro, y una sociedad dependiente y colonizada (Ferrero, 1994 y 2000). Roma y previsiblemente antes de Roma los pueblos del Mediterráneo en la edad del bronce explotaron estas minas y abrieron galerías bajo la tierra. Las norias para evacuar el agua del interior, los malacates en las bocas de los pozos, las escombreras de la época, constituyen hoy elementos patrimoniales emblemáticos del paisaje. (Pérez y Romero, 2004; Pérez y Delgado 2012 y 2014). Los patricios, los soldados, los esclavos y los niños eran el elemento humano del paisaje de las minas.

Tras una larga etapa histórica sin apenas huellas mineras, franceses e ingleses iniciaron a finales del siglo XIX la explotación a cielo abierto mediante cortas (fig. 9) y galerías (fig.10). La corta es una herida profunda, un vaciado poliédrico, multicolor, de escala sobrehumana que se hunde en el interior de la tierra. Ya hemos mencionado que el Andévalo onubense y en menor medida la Sierra están salpicados de estos socavones lunáticos, sobrecogedores por sus dimensiones para cualquier espectador. Para un investigador es una fuente inagotable de curiosidad y estudio multidisciplinar (Gonzalo y Tarín, 1886; Pinedo, 1962; Ferrero, 1994 y 2000 Chapela, 2014). Para un minero representan trabajo, sustento y sufrimiento. Para un 
observador ajeno son elementos que identifican y atestiguan una época histórica. El paisaje minero transporta mentalmente desde esa impresión material a otras sensaciones intangibles, otras épocas, otros modelos sociales y económicos, otra tecnología, otros mecanismos de poder y sumisión. El paisaje de hoy es la transmutación de muchos paisajes anteriores, de todo el proceso histórico-geográfico de configuración minera en Huelva. Hoy, a menudo, son paisajes del abandono, de la soledad y del silencio -cortas abandonadas, edificios hundidos, aldeas desiertas, envejecidas y en ruinas, ferrocarriles abandonados-. Paisajes policromáticos en los que el rojo del gossan llena la vista, pero los colores de las rocas y las sales producen la policromía en que en ocasiones se convierten las cortas y los pozos. Para pintores sensibles, como Manuel Banda, los paisajes mineros son la apoteosis del color y la dureza de la tierra. Él ha sabido captar la estética de estos paisajes de desolación, abandono y rabiosamente coloristas. Para poetas como Rafael Vargas, Patricia Chapela o Ramón Llanes, o novelistas como Concha Espina o Félix Lunar, los paisajes mineros son su fuente de inspiración. Es imposible entender el paisaje de Huelva sin los paisajes mineros y estos no se entienden igual sin estos relatos.

Figura 9

CORTA ATALAYA (MINAS DE RIOTINTO)

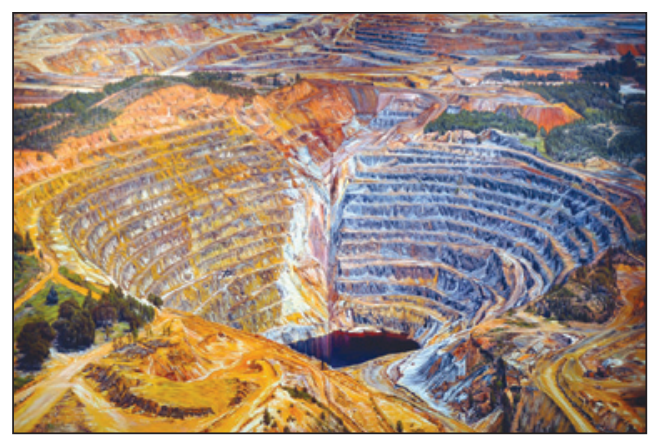

Pinturas: Manolo Banda: La mina emocional.

Figura 11

PAISAJE DEL ABANDONO MINERO. LA ZARZA

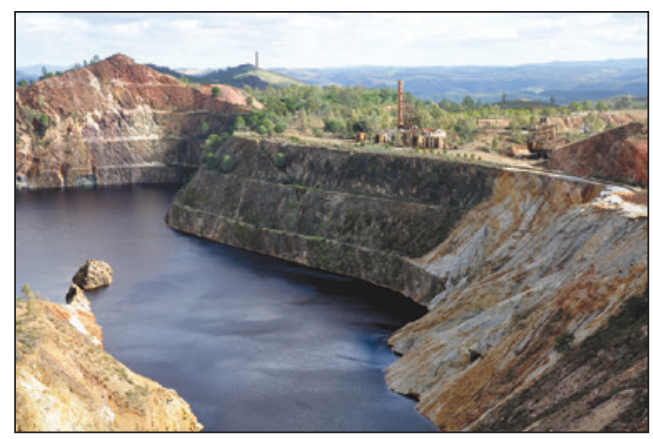

Figura 10 GALERIA SABINA (MINAS DE THARSIS)

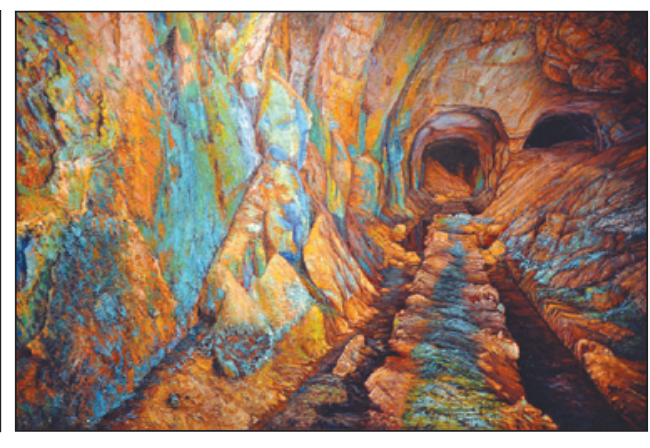

Figura 12

TALLER ZARANDAS. RIOTINTO. ABANDONO MINERO

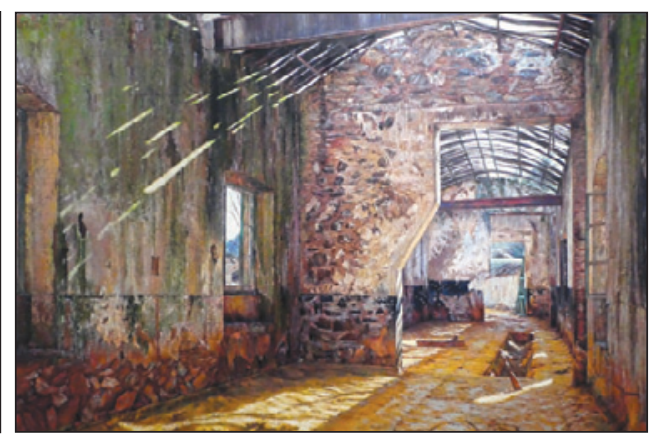

Fotografía: Jesús Monteagudo. Pintura: Manolo Banda: La mina emocional. 


\section{IV.6. Paisajes de campiña}

La campiña agrícola se extiende especialmente por el ángulo suroriental de la provincia, el final del valle del Guadalquivir en su colmatación hacia el SO. Es el ámbito agrícola por excelencia, la Campiña-Condado. Los paisajes de la campiña de Huelva muestran la ocupación de la trilogía mediterránea asociada con otros cereales, legumbres y girasol más los ruedos y las huertas de sus pueblos. Sus formas van desde las costras calizas del río Tinto en Niebla, hasta los glacis de erosión, suaves lomas y tierras abarrancadas por los arroyos y los ríos, que presiden todo el abanico suroriental de esta provincia. El espacio disfruta de llanuras y suelos blandos fácilmente laborables, lo que hará que se nos presente un territorio altamente antropizado, de campos abiertos, aprovechado agrícolamente y que casi hasta épocas históricas haya sido un territorio en formación, inacabado desde el punto de vista físico-natural. Suelos de albarizas donde se asientan las viñas. Materiales calizos, de olivares. Amplios sectores de arcillas, arenas y margas en donde encontramos las tierras de labor de cultivos anuales: cereales diversos, leguminosas, girasol... campos que palpitan de colores, olores y sensaciones al ritmo de las estaciones, desnudos en otoño, verdeando en invierno-primavera, fructificando en primavera-verano y agostándose en pleno verano. Es el ritmo de las tierras de secano, en las que a los cultivos tradicionales de cereal se ha unido el girasol y ha crecido en importancia el garbanzo lechoso de Escacena, llegando ya a ser una IGP. En los ruedos de estos pueblos grandes y blancos, las huertas tradicionales, los pequeños regadíos de frutas y hortalizas de verano, que producían un deseado frescor estival, han ido desapareciendo al ritmo que presionaban e invadían su espacio las urbanizaciones difusas, los adosados, los polígonos industriales y las vías de comunicación.

Con un protagonismo excepcional se sitúan dos paisajes: los del olivar y la vid. El olivo ofrece sus distintos tonos en función de la hora del día y de la estación. Municipios como Gibraleón, Beas, Niebla, Paterna del Campo y Almonte son los máximos representantes de esos paisajes. Aunque Huelva es una de las provincias andaluzas de menor superficie de este cultivo, se alcanzan las 20.000 ha. de olivares en la Campiña. La otra unidad paisajística es la de los viñedos. Responden mayoritariamente a la variedad Zalema. Vides altas, con espalderas, alineadas en los campos abiertos campiñeses de La Palma, Bollullos, Moguer, Rociana, Bonares, Villalba, Almonte y en general de todo el Condado. Las viñas del Condado de Niebla se mezclan con las bodegas y generan una morfología y un cambio estacional en el territorio que ha pasado a formar parte de la esencia patrimonial y paisajística de esta comarca. No en vano el vino del Condado fue el primero que se llevó a América en el primer viaje de Colón y la uva Zalema y sus cepas resistieron como pocas el ataque de la filoxera del siglo XIX. La provincia, especialmente en el Condado, tiene 4.000 has de viñedos bajo la DOP Condado de Huelva.

\section{IV.7. Paisajes en tensión del área periurbana de Huelva}

Como se ha explicado en III.7 y 9, la situación mesopotámica entre el Tinto y el Odiel y abierta a la ría y al océano no sólo hizo a Huelva acreedora de la capitalidad provincial, sino que también en 1964 fue designada cabecera de un Polo de Promoción Industrial químico, petroquímico y metalúrgico que pronto haría crecer su población y multiplicarse su funcionalidad y su accesibilidad. A la vez su entorno periurbano y rururbano y a la larga todo el litoral quedaban intensamente impactados por estos cambios de usos y por este crecimiento 
demográfico. La proximidad de elementos y actividades contrapuestos, incompatibles entre sí o directamente antagónicos forjó un territorio de paisajes en tensión en poca superficie. En menos de $200 \mathrm{Km}^{2}$ encontramos los siguientes elementos antagónicos (fig. 13):

Figura 13

ÁREA PERIURBANA DE HUELVA

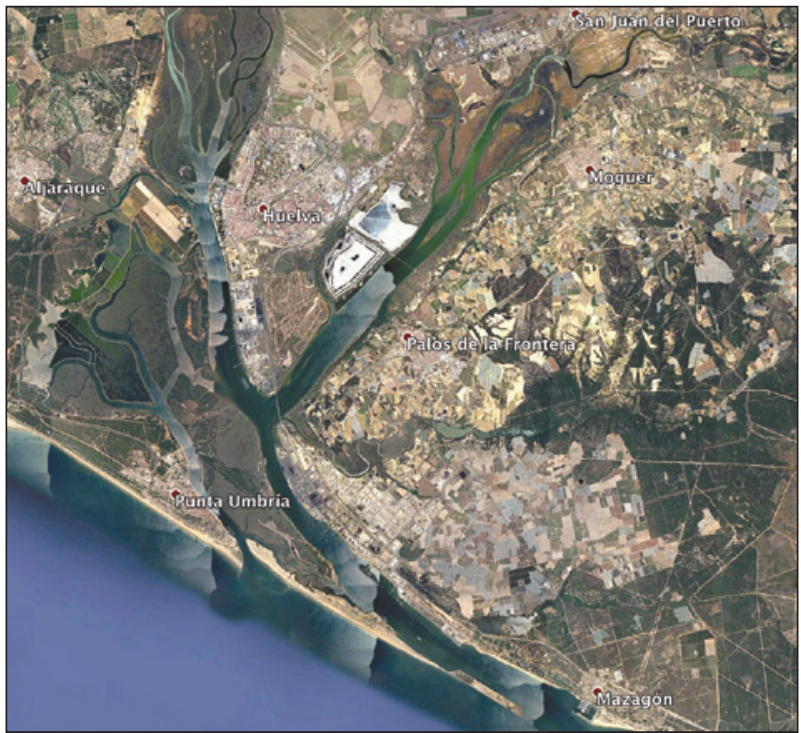

Fuente: Google Earth (tomada julio 2017).

Figura 14

CIUDAD DE HUELVA, POLIGGONO DE LA PUNTA DEL SEBO, FOSFOYESOS ALS Y SE Y MARISMAS

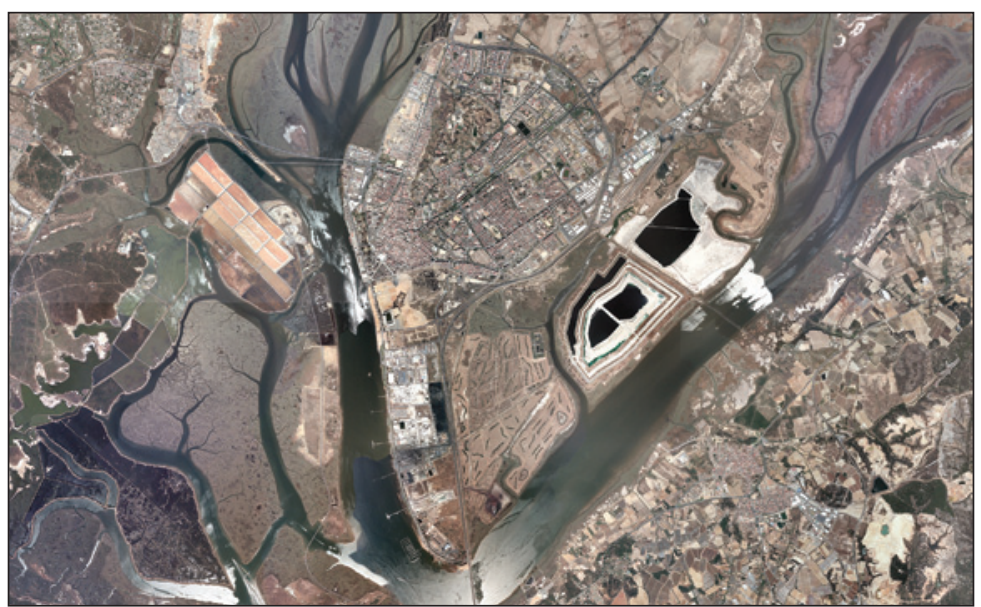

Fuente: IECA. Junta de Andalucía. 2011. 
IV.7.1. Paisaje fluvial mesopotámico entre el Tinto y el Odiel. Explicado con anterioridad. Es uno de los elementos identitarios y patrimoniales de esta provincia. Aquí confluyen las aguas oceánicas atlánticas con las marismas del río Tinto y las extensas y fértiles marismas del río Odiel (10.000 has), Reserva de la Biosfera por la UNESCO, ZEPA y LIC de la Unión Europea. Es un paisaje de la naturaleza, paisaje reliquia, vivo, en realidad paisaje resiliente que conserva la esencia natural pese a las intensas presiones colindantes; paisaje de la serenidad, de la horizontalidad, de la quietud, del color de los amaneceres reflejados en sus aguas, pero, sobre todo, de los atardeceres por poniente, la luz con el tiempo dentro, la Huelva lejana y rosa de Juan Ramón Jiménez.

Envolviendo a las Reservas naturales, el Puerto de Huelva, el más extenso de España, en cuyo interior se encuentran las marismas del Odiel y del Tinto. El puerto es siempre el representante de los paisajes en movimiento, paisaje gigante, tecnológico, de dimensiones sobrehumanas, paisaje tanto histórico -muelles de mineral de las compañías inglesas y francesas del siglo XIX- como actual. En el puerto de Huelva se funden el agua, la industria y la historia. Su bocana vio salir las tres carabelas del descubrimiento en 1492 y ve transitar hoy los mayores metaneros y graneleros del mundo entre pantalanes, depósitos y grúas, mercancías que recorren completo este mundo global (Monteagudo, 1999). El paisaje del puerto es un elemento estructural clave en el desarrollo urbano (Zoido, 2015).

IV.7.2. Paisaje urbano macrocefálico. La ciudad de Huelva, con 145.468 hab., en 2016, representa casi un tercio de la población provincial. Hasta el siglo XXI no había ningún otro núcleo que alcanzase los 20.000 hab., de ahí su carácter macrocefálico respecto al resto de la provincia. Huelva capital constituye un paisaje urbano estrangulado entre dos ríos y entre dos líneas de ferrocarril, que desde el siglo XIX, como umbrales rígidos, la han limitado y condicionado su crecimiento hacia el río y hacia el mar (figs. 13 y 14). Su paisaje urbano es también un paisaje urbano dual, topográfica y socialmente: ciudad alta, el Conquero, como belvedere y alojamiento de clases altas, y ciudad baja, las marismas del Odiel, barrios marginales de origen espontáneo pegados a la lámina de agua del río. Hasta los últimos años, ya en el siglo XXI, Huelva ha sido un paisaje urbano acelerado, anárquico, explosivo, fruto de la rápida demanda de empleo y vivienda para los trabajadores del Polo Industrial en la década de los sesenta del siglo XX. Una ciudad de aluvión, paisaje urbano sin ordenación y sin apenas planificación hasta la década de 1990. A su vez, socialmente se convirtió, hasta la progresiva integración de los inmigrantes, en una ciudad del desarraigo, habitantes que seguían más vinculados a sus lugares de origen que a la propia ciudad onubense. Los rápidos cambios y mejoras acaecidos en la ciudad la han convertido en una ciudad moderna que vive del recuerdo de la imagen urbana colonial de épocas anteriores, paisajes del recuerdo, partiendo de vectores patrimoniales e hitos simbólicos muy potentes: barrio inglés Reina Victoria, muelle de Rio Tinto, Casa Colón, San Pedro, La Merced, El Conquero, La Palmera, El Punto... Como ciudad históricamente portuaria, puerto y ciudad representan en Huelva una historia de encuentros y desencuentros, pero es imposible comprender el paisaje urbano de Huelva sin el paisaje portuario-ferroviario que se entreteje entre sus calles, la limita, la estrangula y a la vez la abre a la ría y al Atlántico (Monteagudo, 1999). 
IV.7.3. Paisaje industrial químico y metalúrgico. La prolongación de Huelva capital hacia el Sur constituye tanto el polígono de la Punta del Sebo (222 has) como el Puerto Interior en la margen izquierda del río Odiel (figs. 13 y 14). Un paisaje que desde 1964 estuvo densamente ocupado y altamente contaminado con productos, subproductos y residuos químicos y metalúrgicos (Fourneau, 1978; Monteagudo 1986, 1992 y 1999). Hoy el polígono de la Punta del Sebo es un paisaje contaminado y abandonado, en donde apenas quedan una decena de fábricas rodeadas de restos de las que en otros momentos formaron parte de esta densa malla industrial. Junto a este polígono un paisaje de desolación y esterilidad, los fosfoyesos ${ }^{17}$, miles de Tm. acumuladas por Fertiberia en 50 años de producción. En imágenes de satélite se comprueba que representan una superficie mayor que la propia ciudad, situados junto a las marismas del río Tinto. El paisaje de este polígono, además de Fertiberia tiene dos protagonistas máximos: la fundición de cobre, plata y oro de Atlantic Coper y la central térmica de Endesa ${ }^{18}$. El paisaje industrial y el puerto continúan hacia el Sur, ya en la ría de Huelva, donde se encuentran tanto el polígono Nuevo Puerto (1.500 has), como el Puerto Exterior, con la refinería de petróleo (Cepsa) a la cabeza, ya en terrenos de Palos de la Frontera, mucho más abierto al océano y más modernizado que el anterior $^{19}$. Todo el conjunto forma un paisaje industrial concentrado, fordista, paisaje productivo y residual, impactante, laboral, contaminado, deteriorado, desolador, inquietante.

\section{IV.7.4. Paisaje histórico. La Rábida (véase apartado IV.9)}

IV.7.5. Paisaje de agricultura intensiva bajo plástico. En estos parajes de Moguer y Palos de la Frontera nació, en gran parte al amparo del Polo y de la agricultura a tiempo parcial, la explotación masiva de fresas y frutos rojos (fig. 15). Antonio Medina Lama, un empresario pionero, desde la finca de Las Madres (una concesión de turba en Moguer), enseñó a los agricultores de estos municipios a a cultivar fresas provenientes de California y a regarlas con tecnologías procedentes de Israel. Genética y riego al amparo de los suelos arenosos, del clima húmedo y cálido de esta costa y del trabajo y el empeño de estos campesinos, fructificaron en la mayor mancha de cultivo de fresas de toda Europa. En días de plena campaña la cooperativa de fresas de Palos de la Frontera procesa un millón de Kg diarios. Este boom ha dado lugar a paisajes que conjugan un mar de plásticos con tecnología hecha paisaje en

17 Miles de toneladas de yeso como residuos para la obtención de ácido fosfórico, atacando la roca fosfórica con ácido sulfúrico obtenido a partir de pirita de hierro, con muy baja ley en cobre. Contienen yeso, ácido sulfúrico, fosforo, uranio y radio. Ocupan una extensión de más de 1200 Has.

18 La metalurgia del cobre es uno de los pilares del Polo de Huelva. Su misión primera era hacer la metalurgia del cobre de las minas de Huelva. Originalmente la fundición fue de la Compañía de Minas de Rio Tinto, Rio Tinto Patiño, Rio Tinto Metal. En 1988 pasó a manos de Atlantic Coper, de la Freeport-McMoRan, una multinacional norteamericana dueña de las principales minas de Indonesia, de donde ahora procede mayoritariamente el mineral concentrado que se transforma en ánodos y cátodos de cobre y lingotes de plata y oro en Huelva.

En la misma Punta del Sebo se encontraba la Central térmica Cristóbal Colón, origen del polígono industrial en 1961, junto a la estatua que preside el extremo Sur de este polígono, en el encuentro del Tinto y el Odiel, dedicada a Cristóbal Colón o la Fe Descubridora, donada por Estados Unidos y realizada por Miss Whitney en 1929. La vieja Central ha sido desmantelada y sustituida por otra mayor, propiedad de la misma compañía, antes Sevillana de Electricidad, ahora Endesa, una central térmica de ciclo combinado de 397,8 MW.

19 En el polígono Nuevo Puerto se concentraba la industria petroquímica o de química orgánica, presidido por la refinería, en los orígenes Rio-Gulf, actualmente Cepsa. A ella se unen derivados del petróleo, como fenoles, producciones de bio-diesel, cada vez en mayor auge (Espejo et al., 2016 y 2017), urea-amoniaco para abonos, Tioxide, productora de pigmentos de óxido de titanio, y otra central termoeléctrica de Unión Fenosa. 
invernaderos, sistemas de riego, plantas, envases, vehículos y personas. Paisaje contrastado según las estaciones, con la gran eclosión de la primavera. Paisaje global y de diversidad humana, de la inmigración, de la tolerancia, de la integración, de la esperanza, pero también de la infidelidad conyugal. Más de 12.000 trabajadores (de los 36.000 que se contratan por temporada para toda Huelva), sobre todo trabajadoras, procedentes de cualquier país del mundo (especialmente de Europa Oriental y Marruecos) conviven aquí durante cuatro intensos meses primaverales. Paisaje de colores, olores y sabores múltiples, pero a la vez paisaje de fuerte impacto visual y ambiental. La deforestación, fertilización química, desinfección con insecticidas y plaguicidas, el uso masivo de los factores limitantes, suelo, agua, energía y residuos, y la proximidad al Polo químico, muestran en estos paisajes la peor de sus caras desde el punto de vista ambiental, lejos, muy lejos, de la sostenibilidad. Son paisajes de la voracidad, de la insostenibilidad, pero también de la convivencia y la solidaridad.

Figura 15

AGRICULTURA BAJO PLÁSTICO / PLÁSTICO, RÍO TINTO Y FOSFOYESOS / INTERIOR DE INVERNADERO DE FRESA
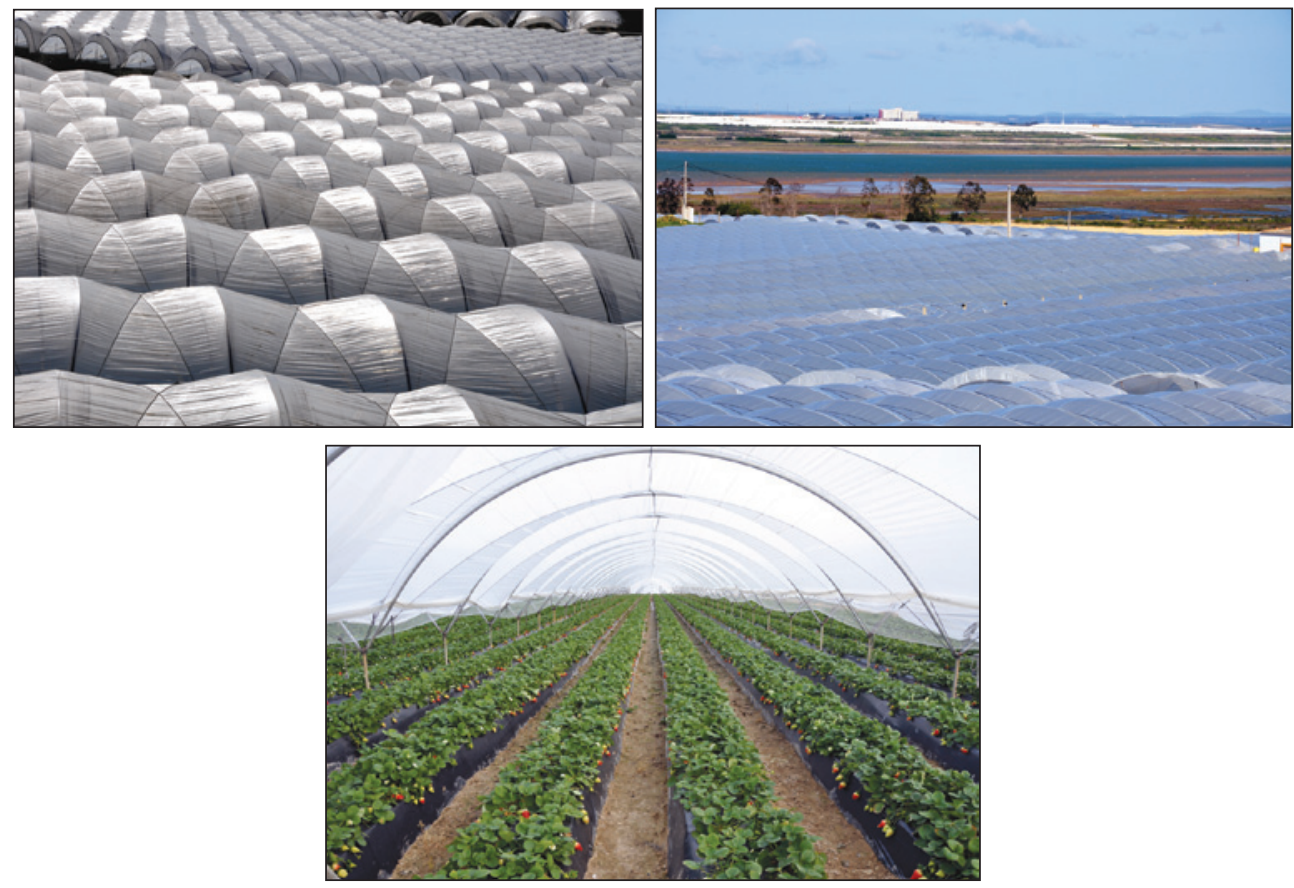

Fotografías: Jesús Monteagudo. Palos de la Frontera.

IV.7.6. Paisaje periurbano del turismo. En este reducido ámbito periurbano hay dos importantes núcleos de segundas residencias y turismo: Punta Umbría (15.000 hab.) y Mazagón (2.000 hab), este mancomunado y gobernado por Palos de la Frontera y Moguer. Son paisajes de litoral atlántico, de playas amplias, casi interminables, de arenas finas, oceánicas. Son también paisajes de ocio, descanso y turismo, paisajes duales de tranquilidad y actividad al aire 
libre, de vida diurna y nocturna, de verano y resto del año. Igualmente, paisajes de urbanizaciones difusas, extensas, que viven los vaivenes de la estacionalidad, infrautilizados en todas las estaciones menos en la estival, en la que se colapsan, multiplicando a veces por 10 su población y su actividad. Punta Umbría, sobre todo, representa también los paisajes del recuerdo. Fue en este núcleo donde comenzó el turismo de sol y playa por parte de los ingleses que explotaban las minas de Riotinto. En el siglo XIX edificaron las primeras viviendas palafíticas de veraneo junto a las chozas de los pescadores. Una de esas viviendas se ha conservado como museo del recuerdo colonial inglés.

\section{IV.7.7. Paisajes urbanos de los núcleos periurbanos}

Los municipios colindantes, además de Punta Umbría, un conjunto periurbano y rururbano (Monteagudo 1986b), han sido transformados por el impacto de la centrifugación urbana de Huelva, por la demanda de viviendas a raíz de la localización del Polo Industrial, por la agricultura intensiva y por el turismo, según los casos. Palos de Frontera y Moguer se han convertido en núcleos de fuerte impacto agrícola y mantienen a Mazagón como segunda residencia y turismo. Son lugares colombinos, de fuerte raigambre en el descubrimiento. El primero aloja en su municipio a La Rábida, el segundo está unido al nacimiento de Juan Ramón Jiménez y por tanto protagonista de su obra, sobre todo de Platero y yo:

Te he dicho, Platero, que el alma de Moguer es el vino, ¿verdad? No; el alma de Moguer es el pan. Moguer es igual que un pan de trigo, blanco por dentro, como el migajón, y dorado en torno -ioh sol moreno!-, como la blanda corteza. (Platero y yo, XXXVIII, El pan)

San Juan del Puerto, próximo a ENCE, ha visto frenado su desarrollo por el repulsivo olor de esta fábrica de celulosas, hoy ya cerrada. Gibraleón y Trigueros, de tradición agrícola olivarera y cerealista, se han transformado menos y han mantenido más su fisonomía y tradición popular y su carácter rururbano. No han llegado a los grados de crecimiento de los núcleos turísticos o de agricultura intensiva. Sus poblaciones oscilan entre los 7.000-20.000 hab. Por último, Aljaraque, que aloja al núcleo de Corrales y a los diseminados de Bellavista y la Dehesa-Golf, conocido como Huelva-2, unido al río Odiel, ha representado la máxima recepción de la centrifugación urbana de Huelva, la especulación inmobiliaria más intensa, el mayor impacto en urbanizaciones difusas y la eliminación de un hábitat minero-portuario, tradicional en Corrales, de la Compañía de Tharsis, construido en el siglo XIX para el alojamiento de los trabajadores de la estiba (Carvajal, 2004). Todo este conjunto está articulado a través de tres ejes: dos puentes sobre el Odiel, uno sobre el Tinto y la autopista A-49 Ayamonte-Sevilla.

\section{IV.8. Paisajes litorales}

A este conjunto central del área urbana y periurbana de Huelva se unen a lo largo de la costa, de Ayamonte a la Punta de Malandar, el resto de los ríos y unidades paisajísticas que ya han sido citados como paisajes del agua. La Costa es el contacto de la provincia con el océano Atlántico e igualmente en tensión como en el caso anterior por la concurrencia de elementos y actividades contrapuestos: 
IV.8.1. Paisajes fluvio-marinos. Costa de $122 \mathrm{Km}$ de longitud, compartimentada y anegada, túrbida el agua marina por las arenas y fangos en su proximidad a la costa. Desde Ayamonte a Doñana, del Guadiana al Guadalquivir, pasando por la desembocadura del Carreras, Piedras, Tinto y Odiel, incluyendo lagunas como Las Madres, de Palos o El Portil (Rodríguez y Núñez, 2015). El agua dulce se funde con la salada y provoca esa horizontalidad y esa dinamicidad mareal cotidiana. Es la Huelva horizontal, anfibia, que cambia de imagen con cada marea, con el amanecer y el atardecer y con las estaciones. La Huelva inacabada, en formación y transformación permanentes. La Huelva de las marismas -Doñana, Odiel, Tinto, Carreras- y flechas o restingas -Carreras, Piedras, Punta Umbría- de todos los ríos citados y de playas amplias con arenas finas y escarpes pronunciados, con dunas y esteros fósiles, y dunas móviles en Doñana, la Huelva de la biodiversidad (Rubio, 1977), pero también de los impactos ambientales provocados por las urbanizaciones, los hoteles, el turismo y la presión humana sobre el borde litoral. Como ya se ha comentado, es la Huelva de Doñana, ampliamente tratada por JF. Ojeda y otros autores (véase bibliografía).

IV.8.2. Paisajes de pinares. Ocupan todo el borde litoral, de Ayamonte a Doñana, siendo más densos en el ámbito de Doñana, donde llegan a formar corrales con las dunas móviles. Se trata del pino piñonero (Pinus pinea), que supera en los municipios costeros las 70.000 has. Agredidos y deforestados en los últimos años por plantaciones bajo plástico y cítricos, por urbanizaciones y por continuos incendios, como el que ha tenido lugar en el verano de 2017, en el que se han calcinado 11.000 has de pinos.

Como en el caso de Moguer, el pino es también protagonista de los paisajes juanrramonianos de Platero y yo:

Tú, si te mueres antes que yo, no irás, Platero mío, en el carrillo del pregonero, a la marisma inmensa, ni al barranco del camino de los montes [...]. Vive tranquilo, Platero. Yo te enterraré al pie del pino grande y redondo del huerto de la Piña, que a ti tanto te gusta [...] Y, todo el año, los jilgueros, los chamarices y los verderones te pondrán, en la salud perenne de la copa, un breve techo de música entre tu sueño tranquilo y el infinito cielo de azul constante de Moguer. (Platero y yo, XI, El moridero) [...]A lo lejos, una cinta de mar, brillante, incolora, vibra, entre los últimos pinos, en un aspecto de paisaje isleño.

(Platero y yo, XXXIV, La novia)

IV.8.3. Paisajes de agricultura intensiva bajo plástico. Son paisajes de agricultura de regadío y plásticos, muy tecnificada, a los que ya se ha hecho referencia anteriormente (IV.7.5). Frutos rojos de fresas, frambuesas, arándanos y moras se extienden en invernaderos interminables por toda la costa superando en el litoral las 5.000 has. A ellas se unen más de 20.000 Has. de cítricos en los municipios litorales, de Ayamonte a Almonte. A menudo colisionan con los factores limitantes, agua-suelo-energía y residuos. En el ámbito de Doñana, cientos de pozos ilegales han estado extrayendo agua para el riego de estas miles de hectáreas de invernaderos y cítricos, poniendo en claro riesgo la propia agricultura y la supervivencia del espacio natural protegido. Como hemos dicho, es sin duda una actividad insostenible y un paisaje en tensión. Pretenden hacer el concepto de desarrollo sostenible sinónimo de crecimiento sostenible, cada año es mayor el 
número de hectáreas necesitadas de riego, cuando la incongruencia es que nada finito puede crecer infinitamente. Como ha repetido insistentemente Miguel Delibes, investigador de la Estación Biológica de Doñana, es cuestión de optar, evidentemente no hay agua para todo, el acuífero 27 no tiene agua para regar, abastecer a miles de habitantes de Matalascañas en verano y mantener las lagunas, los lucios y el agua dulce en Doñana. Es insostenible.

IV.8.4. Paisajes del turismo de sol y playa. Ya han sido mencionados los del área periurbana, pero en este caso la costa de Huelva suma a las cabeceras municipales litorales, los núcleos secundarios, urbanizaciones que, excepto amplios espacios protegidos, se extienden por todo el litoral. Son tanto núcleos compactos que se ensanchan a lo largo de la costa y hacia el interior, casos de Ayamonte, Isla Canela, Punta del Moral, Isla Cristina, La Redondela, La Antilla, El Terrón, El Rompido, El Portil, Punta Umbría, Mazagón, y Matalascañas, como derivaciones y ampliaciones de esos mismos núcleos en urbanizaciones difusas de adosados y chalets exentos, como Costa Esuri en Ayamonte, los ensanches de los núcleos ayamontinos citados anteriormente, Islantilla entre Isla Cristina y Lepe, El Rompido en Cartaya, Nuevo Portil y Pinos del Mar en Punta Umbría y el crecimiento constante de Mazagón y Matalascañas, este en el borde mismo de Doñana, limitado su crecimiento litoral por el espacio protegido. En general se trata de paisajes urbanos abigarrados y densos, de edificios bajos, viviendas unifamiliares y a menudo dentro de la línea marítimo-terrestre, ocupando de forma privada el espacio público de la playa. Paisajes de vaivén, hiperactivos y colmatados de vecinos, turistas y actividad en verano y casi vacíos y sin vida el resto del año. Paisajes voraces, consumidores de los tres factores limitantes: suelo, agua y energía y grandes productores de residuos. De los 519.639 hab. de la provincia de Huelva en 2016, los municipios con litoral atlántico, excluyendo los 145.468 hab. de Huelva capital, tenían una población censada de 182.650 hab. En verano esa población se multiplica como mínimo por cinco, aproximándose al millón de habitantes veraniegos, lo que da idea de la presión sobre los recursos de forma puntal y estacional, especialmente en la estación en la que menos agua hay. Únase a lo descrito aquí todo lo que se ha analizado de los paisajes litorales.

\section{IV.9. Paisajes mágicos, sagrados, del recogimiento, del aislamiento, de la meditación}

La provincia de Huelva, como ya ha sido presentada, ha sido siempre tierra mágica, sagrada y de aislamiento, desde los primitivos dólmenes hasta nuestros días. Paisajes que incorporan las fuerzas telúricas de los promontorios, el agua purificadora, las oquedades, los bosques, los cerros, la naturaleza virgen, singularizada y apartada, en definitiva, donde fundirse con la divinidad y meditar sobre lo trascendente. Paisajes de santuarios tartésicos, romanos, visigodos, musulmanes y católicos. Paisajes de templos, ermitas y monasterios, de vírgenes y apariciones, hoy paisajes de patronas y patrones, de fiestas y romerías.

Destaca La Rábida - ribāt, rābița, rāpița- Como proa de barco, el promontorio de La Rábida se asoma al río Tinto y mira al Suroeste, al Atlántico, a América. Este paraje emblemático está presidido por el convento franciscano -monasterio en el argot popular- protagonista del descubrimiento colombino de América y es uno de los vectores paisajísticos patrimoniales más importantes de la provincia de Huelva, declarado $\mathrm{BIC}^{20}$. Antiguo templo ibérico de la diosa

20 La Rábida ha solicitado ser integrado en la lista del Patrimonio Mundial de la UNESCO y le ha sido denegada la propuesta alegando su excesiva proximidad al área industrial química. 
Erebea, templo romano, morabito mudéjar, ermita, fortaleza militar o religiosa de frontera, hoy es uno de los muchos lugares mágicos, sagrados, simbólicos, aislados, fundidos con la naturaleza en Huelva, pero de todos ellos el de mayor protagonismo histórico y simbólico (Ortega, 1980; Santamaría, 1991). En el paisaje histórico de La Rábida confluyen muchos elementos que lo reconocen y lo identifican: paisaje artístico y patrimonial-claustro mudéjar, frescos de Daniel Vázquez Díaz-, sagrado, del recogimiento, de la meditación, del estudio, universitario. Situado sobre la margen izquierda del río Tinto, santuario de la Virgen de Los Milagros o de La Rábida, venerada por los marineros del primer viaje colombino. Fue abandonado el convento tras la desamortización y salvado de la demolición en 1851 por Mariano Alonso Castillo, el gobernador Alonso, quien además se ocupó de su rehabilitación. Hoy es un paraje que tiene como protagonista al monasterio, pero que ha creado un parque temático en torno a la reproducción exacta de las carabelas colombinas y la botánica de Celestino Mutis. En el emblemático paraje se aloja la Universidad Internacional de Andalucía.

Figura 16

MONASTERIO DE LARÁBIDA

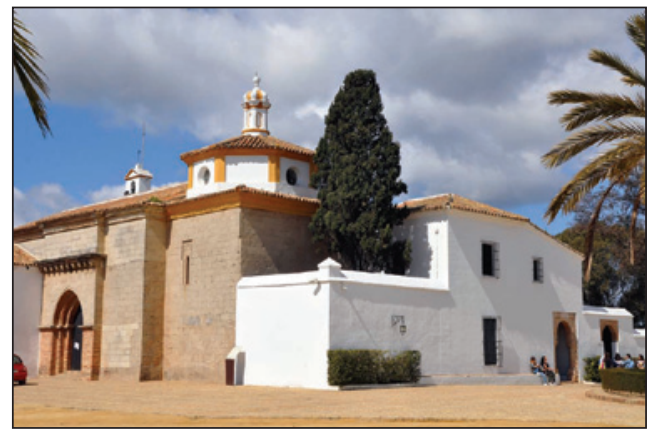

Fotografías: Jesús Monteagudo.
Figura 17

ERMITA DE LA VIRGEN DE EL ROCIOO

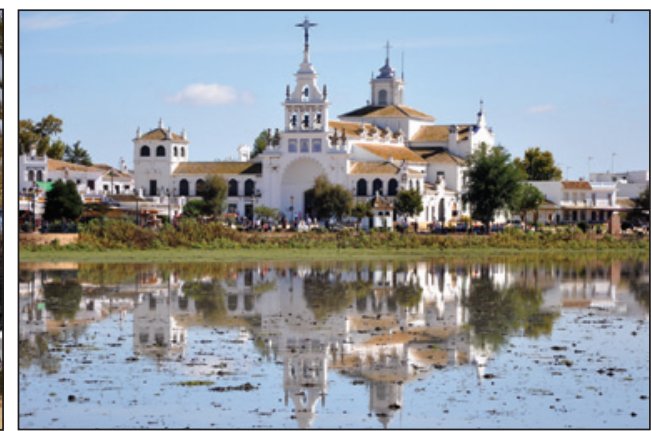

Si no de trascendencia universal, sí de fama nacional e internacional, le sigue en importancia el santuario de la Virgen de El Rocío en el entorno de Doñana. Es la madre del agua, la reina de las marismas, la blanca paloma, el emblema de ese mundo mítico marismeño que tan bien han explicado Juan Ojeda, Caballero Bonald, Juan y Águeda Villa, Juan Manuel Suárez Japón, Isidoro Moreno... Pocos santuarios, paisajes y romerías han sido tanto y tan profundamente analizados como El Rocío. En la aldea de El Rocío convergen en el domingo de pentecostés centenares de miles de personas, caballos, charrés, caravanas y carrozas en un espectáculo multicolor, que transforma durante una semana las marismas del Guadalquivir. Pone en funcionamiento todos los sentidos y va más allá de lo meramente sensorial. El paisaje de El Rocío en plena romería o fuera de ella transporta a creyentes y no creyentes a un mundo intangible tanto o más que a la propia materialidad de la fiesta, la ermita y el paraje.

La lista sería muy larga, pero es preciso resaltar los paisajes adscritos a santuarios y ermitas de la Sierra y el Andévalo, cuya localización, emplazamiento, paisaje y antropología merecen atención y estudio detenido más allá de estas páginas. Son los casos de Nuestra Señora de los Ángeles en la Peña de Arias Montano; Santa Eulalia de Almonaster la Real; 
San Mamés, sobre la ciudad de Turóbriga, en el Llano de la Belleza, Aroche; la Virgen de la Peña en el Cerro del Águila, Puebla de Guzmán; Virgen de Piedras Albas, en el Prado de Osma, El Almendro-Villanueva de los Castillejos; San Benito Abad, en los Montes de San Benito, Cerro del Andévalo; Virgen de la Coronada, Sotiel Coronada, Calañas; Virgen de Montemayor, Moguer, uno de los parajes juanrramonianos descritos en Platero y yo...

\section{IV.10. Paisajes emergentes de las energías renovables}

Concluimos esta síntesis con un paisaje que se sobreimpone cada vez con mayor frecuencia a varios de los aquí descritos. Se trata del paisaje que Prados et. al. (2012) y Frolova et al. (2014) llaman paisajes emergentes de las energías renovables. En el Andévalo y la Costa, sobre todo, se extienden cada vez con mayor profusión "huertos solares" que inundan de placas solares las fincas, como girasoles móviles buscando la luz. Las zonas de colinas elevadas del Andévalo aparecen colonizadas, y visibles desde cualquier otero, por importantes extensiones de aerogeneradores. Se multiplican en la raya portuguesa y en todo el Andévalo occidental donde es constante el viento de poniente y el juego de microclimas. Las laderas de umbría y las solanas se suceden deforestadas en este ámbito próximo al Guadiana-Chanza y se cubren de aerogeneradores.

\section{CONCLUSIÓN}

En breves páginas se ha expuesto un mosaico de paisajes de la provincia de Huelva, de la montaña al mar. Lo analizado es sólo el punto de partida de trabajos individualizados para cada una de estas unidades paisajísticas. En ciertos casos algunos de estos paisajes han sido estudiados profundamente por otros investigadores ya citados. Se pretendía como objetivo, en este trabajo breve, mostrar de forma sintética la variedad y riqueza paisajística de la provincia y las distintas formas y enfoques como se pueden abordar, haciendo una enumeración de los principales paisajes, destacando sus claves comprensivas e interpretativas espaciales y territoriales, su localización, su extensión, sus límites, sus principales componentes, sus contrastes, sus atributos, su singularidad y su estética, su esencia o núcleo de sentido. Lo que presentamos permite concluir que estamos ante un espacio y un territorio que por su singularidad hidrológica e hidrográfica, su confinamiento, su carácter fronterizo, su contraste antigüedad/juventud geológica y su fuerte antropización a lo largo de la historia, permite identificar una gran riqueza de unidades paisajísticas individualizadas, pero a la vez superpuestas y solapadas unas con otras, en algunos casos casi como endemismos naturo-culturales por su aislamiento. A lo aquí analizado hay que añadir los relatos que estos paisajes generan. Serán objeto de trabajos posteriores.

\section{BIBLIOGRAFÍA}

ALCÁNTARA, J. y MUÑOZ, J.M. (2015): “Clasificación del paisaje de Huelva (España): Un método objetivo de identificación y caracterización”, Estudios Geográficos, n 279, 447-471. BERQUE, A. (2009): El pensamiento paisajero. Madrid, Biblioteca Nueva.

BORJA, F. y DÍAZ DEL OLMO, F. (1995): "Niveles marinos y evolución de líneas de costa del litoral suratlántico andaluz (post-6000 BP)", Revista de Estudios Andaluces, n 21, 217-222. 
CANALES, G. y PONCE, M.D. (2016): Pareceres sobre la Huerta del Bajo Segura. El poder de la identidad y la cultura en la valoración del paisaje. Alicante, Univ. de Alicante.

CARRIAZO RUBIO, JL. (2008): "Mil años de fortificaciones en el occidente andaluz: Castillos de Huelva", Andalucía en la historia, nº. 22, 88-93.

CARRIAZO RUBIO, JL. y MIURA ANDRADES, J.M. (Coords.)(1998): Huelva en la Edad Media: reflexiones, aportaciones y nuevas perspectivas veinte años después. Huelva, Univ. de Huelva.

CARRIAZO RUBIO, JL., PALMIERI, N. y CUENCA LÓPEZ, J.M. (2004): Huelva, tierra de castillos. Huelva, Diputación de Huelva.

CARVAJAL QUIRÓS, JM. (2004): Corrales, azufre, cobre y río. De enclave minero a población dormitorio. Punta Umbría, Ed. el autor.

CHAPELA CABRERA, P. (1999): "Las primeras infraestructuras: de los muelles de mineral al muelle de Levante". En MONTEAGUDO, J.: El Puerto de Huelva. Historia y Territorio. Huelva, Univ. Huelva. Autoridad Portuaria, 97-112.

CHAPELA CABRERA, P. (2014): El patrimonio minero. Desarrollo y dinamización territorial en la comarca del Andévalo occidental: Tharsis (Alosno. Huelva). Trabajo Fin de Máster. Inédito.

CHASTAGNARET, G. (2017): De fumées et sang. Pollution minière et massacre de masse. Andalousie-XIXe siècle. Madrid, Casa de Velázquez.

CONVENIO (CONVENCIÓN) EUROPEO DEL PAISAJE (2000). Florencia, 20/10/2000. Entró en vigor el 01/03/2004/. Fue ratificado por España 26/11/2007 y entró en vigor en España 01/03/2008. http://www.mecd.gob.es/cultura-mecd/dms/mecd/cultura-mecd/areascultura/patrimonio/Convenio_europeo_paisaje.pdf (consultado el 15 de mayo de 2017).

COSGROVE, D. (2002): “Observando la naturaleza: el paisaje y el sentido europeo de la vista", Boletín de la Asociación de Geógrafos Españoles, n 34, 63-89.

El Andévalo. Actas de las Jornadas de Patrimonio del Andévalo, I-V. 2010-2014. Diputación Provincial de Huelva.

El olivar andaluz (2003). Sevilla, Consejería de Agricultura y Pesca, Junta de Andalucía.

ESPEJO, C., MILLÁN, D. y GARCÍA, R. (2016): “Contribución al estudio del sector de los biocarburantes en España, Scripta Nova, no 548, 1-40. http://www.ub.edu/geocrit/sn/ sn-548.pdf

ESPEJO, C., SERRANO, J.M. y PARRA,A. (2017): "La industria de refino del petróleo en Cartagena (España)", Anales de Geografía de la Universidad Complutense, no 37 (2), 371-398.

ESPINA, Concha (1996): El metal de los muertos. Huelva, Fundación Rio Tinto, Dip. Provincial, Univ. de Huelva (original de 1920).

FERNÁNDEZ, J; ROLDÁN, F. y ZOIDO, F. (Coords.) (2003): Territorio y Patrimonio. Los Paisajes Andaluces. Sevilla. Instituto Andaluz de Patrimonio Histórico, JA.

FERRERO BLANCO, M.D. (1994): Capitalismo minero y resistencia rural en el suroeste andaluz. Riotinto 1873-1900. Huelva, Diputación Provincial de Huelva (2º ed. 1999, Univ. de Huelva).

FERRERO BLANCO, M.D. (2000): Un modelo de minería contemporánea. Huelva, del colonialismo a la mundialización. Huelva, Univ. de Huelva.

FOURNEAU, F. (1978): El impacto del polo en la provincia de Huelva (1964-74). Sevilla, IDR. 
FROLOVA, M.; ESPEJO, C.; BARAJA, E. y PRADOS, MJ. (2014): "Paisajes emergentes de las energías renovables en España". Boletín de la Asociación de Geógrados Españoles, ${ }^{\circ}$ $66,223-252$.

GÓMEZ, J. y RIESCO, P. (2010): Marco conceptual y metodológico para los paisajes españoles. Aplicación a tres escalas espaciales. Sevilla, CEPT, Consejería de Obras Públicas y Vivienda, Junta de Andalucía.

GONZALO Y TARÍN, J. (1886): Descripción física, geológica y minera de la provincia de Huelva. Madrid, Memorias de la Comisión del Mapa Geológico de España. 2 vols.

GOZÁLVEZ, JL. (1982): La formación de la provincia de Huelva y el afianzamiento de su capital. Huelva, Diputación provincial.

GOZÁLVEZ, J.L. (1999): "Las pesquerías en el puerto de Huelva. Siglos XVI-XIX”. En MONTEAGUDO, J.: El Puerto de Huelva. Historia y Territorio. Huelva, Univ. Huelva. Autoridad Portuaria, 75-86.

GUZMÁN ÁLVAREZ, J.R. (Coord.) (2008): Paisaje vivido, paisaje estudiado. Miradas complementarias desde el cine, la literatura, el arte y la ciencia. Córdoba, Universidad de Córdoba, Consejería de Medio Ambiente, JA.

JIMÉNEZ, Juan Ramón (2014): Platero y yo. Madrid, Anaya (edición con motivo del centenario de su publicación, 1914-2014).

JURADO, J.M. y PAZOS, F.J. (2016): 'Población y turismo rural en territorios de baja densidad demográfica en España', Boletín de la Asociación de Geógrafos Españoles, 71, 247272.

LADERO QUESADA, M.A. (Coord.)(1976): Huelva en la Andalucía del siglo XV. Huelva, IEO.

LUNAR, Félix (1991): A cielo abierto. De Riotinto a Norteamérica. Aroche, Ayuntamiento y Asoc. Cultural Sanabria (original 1955).

MADERUELO, J. (2005): El paisaje. Génesis de un concepto. Madrid, Abada.

MADERUELO, J. (Coord.)(2010): Paisaje y patrimonio. Madrid, Abada.

MÁRQUEZ FERNÁNDEZ, D. (1975): La geo-economía forestal de Huelva y el dilema de sus eucaliptales. Sevilla, IDR, Univ. Sevilla.

MARTÍNEZ DE PISÓN, E. (2010): "Saber ver el paisaje”, Estudios Geográficos, 269, 395-414.

MATA OLMO, R. (2007): 'Paisaje y territorio. Un desafío teórico y práctico' En $V$ Congreso Internacional de Ordenación del Territorio. Agua, Territorio y Paisaje. De los instrumentos programados a la planificación aplicada, 999-1037 http://www.fundicot.org/v-ciot

MATA OLMO, R. (2016): "Editado el Catálogo de paisajes de la provincia de Sevilla, el primero de los catálogos andaluces de paisaje", Boletín de la AGE n70, 539-544.

MATA, R. y SANZ, C. (Dirs.) (2003): Atlas de los paisajes de España. Madrid, Minist. Med. Ambiente.

MENANTEAU, L y VANNEY, JR. (1985): Mapa fisiológico del litoral atlántico de Andalucía. Sevilla, Consejería de Política Territorial, Junta de Andalucía.

MOLINERO, F.; OJEDA, J.F. y TORT, J. (Coords.) (2011): Los paisajes agrarios de España. Madrid, Min. Medio Ambiente, Medio Rural y Marino.

MOLINERO, F.; TORT, J.; OJEDA, JF.; RUIZ, E.; MARTÍNEZ, E.; SILVA, R. y MATA, R. (Coords.) (2013): Atlas de los paisajes agrarios de España. 2 Vols. Madrid, MAGRAMA

MOLINERO, F.; TORT, J.; MATA, R.; SILVA, R.; GARCÍA, J.L.; PORCAL, M.C. y RUIZ, E. (Coords.) (2017): Paisajes patrimoniales de España. 2 vols. Madrid, MAGRAMA 
MONTEAGUDO, J. (1987a): Comarcalización y organización del territorio en la provincia de Huelva. Huelva, COCIN de Huelva.

MONTEAGUDO, J. (1987b): El entorno agroindustrial de Huelva. Huelva, COCIN de Huelva.

MONTEAGUDO, J. (1992): ‘Territorio y función en los núcleos de la Costa de Huelva'. En Feria, J.M. (Coord.): Jornadas sobre ciudades medias. Sevilla, Consejería de Obras Públicas y Transportes, JA, 103-120.

MONTEAGUDO, J. (Coord.) (1999): El Puerto de Huelva. Historia y Territorio. Huelva, Autoridad Portuaria de Huelva-Univ. de Huelva.

MORA-FIGUEROA, L. de (1981): Torres de Almenara de la Costa de Huelva. Huelva, IEO.

NOGUÉ, J. (2010): “El paisaje en la ordenación del territorio. La experiencia del Observatorio del Paisaje de Cataluña", Estudios Geográficos, 269, 415-448

NOGUÉ, J. y SAN EUGENIO, J. de (2017) 'La contribución del paisaje visual en la generación de marcas territoriales', Boletín de la Asociación de Geógrafos Españoles, n 74, 143-160.

OJEDA RIVERA, J.F. (1987): Organización del Territorio en Doñana y su entorno próximo (Almonte), siglo XVIII-XX. Madrid, ICONA.

OJEDA RIVERA, J.F. (2013a): "Lectura transdisciplinar de paisajes cotidianos, hacia una valoración patrimonial. Método de aproximación” Revista Invi, n 78, vol. 28, pp. 25-75.

OJEDA RIVERA, J.F. (2013b): “Claves comprensivas de los paisajes andaluces". Revista de Estudios Regionales, 96, 21-31

OJEDA RIVERA, J.F. (Coord.) (2015): Doñana, el paisaje relatado. Granada, Entono Gráfico.

OJEDA, J.F.; GONZÁLEZ, J.C. y LÓPEZ, A. (Coords.) (2006): Doñana en la cultura contemporánea. Madrid, Organismo Autónomo Parques Nacionales, Ministero de Medio Ambiente.

OJEDA, J.F. y SILVA, R. (1997): “Dehesas de Sierra Morena y políticas agroambientales comunitarias", Estudios Geográficos n ${ }^{\circ}$ 227, 203-226.

OJEDA, J.F. y SILVA, R. (2002a): “Aproximación a los paisajes de la Sierra Morena Andaluza”. En ZOIDO, F. y VENEGAS, C. (Coords.): Paisaje y ordenación del territorio, Sevilla, Consejería de Obras Públicas y Transportes, JA.-Fundación Duques de Soria, 71-91.

OJEDA, J.F. y SILVA, R. (2002b): 'Efectos de la implantación del modelo agroambiental y postproductivista en la Sierra Morena Onubense', Estudios Geográficos n ${ }^{\circ} 246,69-100$

ORTEGA, Padre Ángel (1980): La Rábida. Historia documental crítica. Huelva IEO, Dip. Huelva. Vols. I-IV (ed. facsímil, original 1925).

ORTEGA CANTERO, N. (2016): "El lugar del paisaje y su valoración en la geografía española moderna: de Rafael Torres Campos a Manuel de Terán”, Estudios Geográficos, 281, 595-617.

PAREJO, C. y SERVETO, P. (2008): Paisajes de Huelva. Huelva, Diputación de Huelva.

PÉREZ MACÍAS, JA. y CARRIAZO RUBIO, J.L. (Coords.) (2005): La banda gallega: conquista y fortificación de un espacio de frontera (siglos XIII-XVIII). Huelva, Univ. de Huelva. PÉREZ, JA. y DELGADO, A. (2012): "Paisaje y territorio de Riotinto en época romana". En ZARZALEJOS, M.M. et al. (Coords.): Paisajes mineros antiguos en la Península Ibérica, 47-68. PÉREZ, J.A. y DELGADO, A. (2014): "La minería romana en el Suroeste Ibérico". Cuadernos de prehistoria y arqueología de la Universidad de Granada $\mathrm{n}^{\circ}$ 24, 239-265.

PÉREZ, J.A. y ROMERO, E. (Eds.)(2004): Metallum. La minería suribérica. Huelva, Univ. Huelva. 
PILLET, F.; CAÑIZARES, C. y RUIZ, A. (eds.): Territorio, paisaje y sostenibilidad. Un mundo cambiante. Barcelona, Ediciones del Serbal.

PINEDO VARA, I. (1962): Las piritas de Huelva. Madrid, Summa.

PRADOS, M.J. y DEL VALLE, C. (2010): "Naturbanización y cambios en la población de los espacios naturales de Doñana y Sierra Nevada". Documents d'Anàlisi Geogràfica, vol. 56, $\mathrm{n}^{\mathrm{o}} 3,435-460$.

PRADOS, M.J. BARAJA, E; FROLOVA, M. y ESPEJO, C. (2012): “Integración paisajística y territorial de las energías renovables". Ciudad y Territorio: Estudios Territoriales $\mathrm{n}^{\circ}$ 171, 127-143.

REY, R; GONZÁLEZ, D.; LARA, M.J. y PEÑA, MA. (1995): El tiempo y las fuentes de la memoria. Historia moderna y contemporánea de la provincia de Huelva. Huelva, Dip. Prov. Huelva, 3 vols.

RICHARDSON, H. (1976): Políticas y planificación del desarrollo regional en España. Madrid, Alianza.

RODRÍGUEZ, J. y NÚÑEZ, C. (Eds.) (2015): El litoral de Andalucía. Huelva, Univ. de Huelva.

RUBIO RECIO, J.M. (1977): "Nota sobre la significación biogeográfica y los problemas de las marismas del Guadalquivir y su parque nacional”. Cuadernos Geográficos, nº 7, 277-292.

SANTAMARÍA, B. (1991): Huelva y La Rábida. Huelva, Univ. Hispanoamericana de La Rábida. ed. facsímil (original 1882).

SÁÑEZ REGUART, A. (1791-95): Diccionario histórico de los artes de pesca nacional. 5 vols. Madrid.

SILVA PÉREZ, R. (2009): “Agricultura, paisaje y patrimonio territorial. Los paisajes de la agricultura vistos como patrimonio", Boletín de la Asociación de Geógrafos Españoles $\mathrm{n}^{\circ}$ 49, 309-334.

SILVA, R. y JOVER, J. (2016): "Los paisajes patrimoniales de la Sierra de Huelva. Ensayo metodológico", Estudios Geográficos, n ${ }^{\circ} 281,647-670$.

SILVA, R, FERNÁNDEZ, V. y MATA, R. (2017): "Concepto, ámbito y significado de los paisajes patrimoniales”. En F. Molinero, J. Tort, R. Mata, R. Silva, J. L. García, M.C. Porcal y E. Ruiz (Coords.) (2017): Paisajes patrimoniales de España. Madrid, MAGRAMA, vol. 1, 17-38.

TERRERO, J. (1952 y 1954): “La tierra llana de Huelva”. Estudios Geográficos, no 49, 671$698 ; n^{\circ} 54,5-57$.

ZOIDO NARANJO, F. (Dir.) (2005): “Mapa de los paisajes de Andalucía”. En Atlas de Andalucía, Vol. II. Sevilla, CEPT, Junta de Andalucía.

ZOIDO NARANJO, F. (2012): "El paisaje un concepto útil para relacionar estética, ética y política", Scripta Nova, 407.

ZOIDO NARANJO, F. (Dir.) (2015): El paisaje en la ordenación y gestión de los puertos de Andalucía. Sevilla, Centro de Estudios Paisaje y Territorio: Consejería de Medio Ambiente y Ordenación del Territorio.

ZOIDO NARANJO, F. (2016): "El paisaje, fundamento de un buen gobierno del territorio". Boletín de la Institución Libre de Enseñanza, n 102-103, 41-60.

ZOIDO, F. y VENEGAS, C. (Coords.) (2002): Paisaje y ordenación del territorio, Sevilla, Consejería de Obras Públicas y Transportes, Junta Andalucía-Fundación Duques de Soria

ZOIDO, F. y RODRÍGUEZ, J. (Dirs.) (2015): Catálogo de paisajes de la provincia de Sevilla. Sevilla, CETP, Junta de Andalucía. 